\title{
Dendritic Cells in the Cross Hair for the Generation of Tailored Vaccines
}

\author{
Laura Gornati', Ivan Zanoni ${ }^{1,2}$ and Francesca Granucci ${ }^{1 *}$ \\ ${ }^{1}$ Department of Biotechnology and Biosciences, University of Milano-Bicocca, Milan, Italy, ${ }^{2}$ Division of Gastroenterology, \\ Harvard Medical School, Boston Children's Hospital, Boston, MA, United States
}

\section{OPEN ACCESS}

Edited by:

Piergiuseppe De Berardinis, Istituto di biochimica delle proteine (IBP), Italy

Reviewed by: Raffaele De Palma, Università degli Studi della Campania "Luigi Vanvitelli" Caserta, Italy Federica Moschella, Istituto Superiore di Sanità, Italy Antonio Leonardi, Università degli Studi di Napoli Federico II, Italy

*Correspondence: Francesca Granucci francesca.granucci@unimib.it

Specialty section: This article was submitted to Molecular Innate Immunity, a section of the journal

Frontiers in Immunology

Received: 21 February 2018 Accepted: 14 June 2018 Published: 27 June 2018

Citation: Gornati L, Zanoni I and Granucci F (2018) Dendritic Cells in the Cross Hair for the Generation of Tailored Vaccines.

Front. Immunol. 9:1484. doi: 10.3389/fimmu.2018.01484
Vaccines represent the discovery of utmost importance for global health, due to both prophylactic action to prevent infections and therapeutic intervention in neoplastic diseases. Despite this, current vaccination strategies need to be refined to successfully generate robust protective antigen-specific memory immune responses. To address this issue, one possibility is to exploit the high efficiency of dendritic cells (DCs) as antigen-presenting cells for T cell priming. DCs functional plasticity allows shaping the outcome of immune responses to achieve the required type of immunity. Therefore, the choice of adjuvants to guide and sustain DCs maturation, the design of multifaceted vehicles, and the choice of surface molecules to specifically target DCs represent the key issues currently explored in both preclinical and clinical settings. Here, we review advances in DCs-based vaccination approaches, which exploit direct in vivo DCs targeting and activation options. We also discuss the recent findings for efficient antitumor DCs-based vaccinations and combination strategies to reduce the immune tolerance promoted by the tumor microenvironment.

Keywords: dendritic cells, vaccination, pattern recognition receptors, antigen delivery, adjuvants

\section{INTRODUCTION}

Vaccines represent one of the most effective Copernican revolutions for humankind and world health. This innovative discovery by Edward Jenner in the late years of the XVIII century allowed for control or complete eradication of infectious diseases as smallpox (1979) and rinderpest virus (2011) (1). This immunization strategy posed the bases for current remarkable therapeutic approaches against not only infections but also cancer. In evolutionary terms, pathogens have acquired the capability to circumvent the immune system with several evasion mechanisms, revised elsewhere (2), that prevent pathogen clearance and the establishment of immune memory. Vaccines represent the unique tool we have to impede pathogen spread; therefore, the urgent need for efficient vaccines is as relevant as before. Mycobacterium tuberculosis, which causes tuberculosis, is currently one of the most feared infectious agent due to its capability to evade the immune system, leading to death of more than one million of people per year. Unbelievably, the only licensed vaccine against Mycobacterium tuberculosis is bacillus Calmette-Guérin (BCG) conceived about 100 years ago. Nonetheless, BCG has displayed some degree of inefficacy in humans, thus raising the need for new tailored vaccination strategies that are currently under investigation (3). Moreover, every year, new cases of human immunodeficiency virus (HIV) infections lead to the necessity of a vaccine to control and prevent the spread of the virus. Up to now, vaccines against HIV have not passed phase II clinical trials due to poor protection conferred, requiring revision of delivered antigens (ags) and strategy to improve T cell response (4). Moreover, the recent outbreaks of Ebola virus and Zika virus infections clearly demonstrate that still nowadays 
more than few infectious diseases need to be overwhelmed, as reported by the World Health Organization. On the other hand, vaccines represent also a therapeutic tool against cancer. One of the hallmarks of cancer is the capability of tumor cells to evade immune-mediated destruction (5) by promoting a tolerant milieu. Therefore, the immune system has to be pushed to respond specifically and robustly against tumors cells.

To address this purpose, it is becoming more and more evident that dendritic cells (DCs) stand out as a potent tool in our hands, being the mediators of cellular and humoral responses (6). DCs have been discovered in 1973 by R. Steinman and Z. Cohn that divided phagocytic cells (discovered by E. Metchnikoff in 1887) in macrophages and DCs on the basis of different effector functions: microbial scavenging activities for macrophages and antigen-presenting function for DCs $(7,8)$. Since then, DCs have emerged as the most potent antigen-presenting cells capable of shaping adaptive responses both during infections and cancer. Moreover, the broad spectrum of DCs activation makes them suitable for fine shifting of the type of response the context needs. Taking advantage of new adjuvants, innovative ags-delivery carriers and targeting strategies, it is now feasible to optimize the activation and ag presentation processes by the specific DCs subset that is the most effective in the initiation of the adaptive response needed in a given context. Here, we discuss the diverse phenotypical and functional properties of DCs subtypes that are exploited by recently developed vaccine approaches, dealing with advances in the use of ags, adjuvants, carriers and DCs-expressed molecules, object of targeting.

\section{DCs IDENTITY: A MULTIFACETED FUNCTIONAL FAMILY}

Dendritic cells are the primary professional antigen-presenting cells (APCs) that reside in both lymphoid and non-lymphoid organs (9-11). DCs encompass several heterogeneous subsets whose subdivision relies on ontogeny, expression of surface-receptors, and transcription factors (12-14). Much effort has been done in the identification and characterization of tissue-specific DC subsets to unravel the correlation between phenotype, localization, and functional properties, both in health and disease. Initially, DCs have been classified into conventional DCs (cDCs) and plasmacytoid DCs (pDCs). Briefly, cDCs prime naïve $\mathrm{T}$ cells and orchestrate ag-specific adaptive responses, while pDCs intervene during viral infections producing type I interferons (IFNs). Advanced approaches have extremely pushed our understanding of DC biology, resulting in a recent readapted taxonomy $(12,15,16)$. Indeed, Villani and colleagues identify six subsets of DCs and monocytes in human (Figure 1): DC1 (CLEC9A $\left.{ }^{+} \mathrm{CD} 141^{+} \mathrm{DCs}\right), \mathrm{DC} 2$ and DC3 (CD1c ${ }^{+}$DCs), DC4 (FCGR3A/CD16 $\left.{ }^{+} \mathrm{DCs}\right), \mathrm{DC} 5$ $\left(\mathrm{AXL}^{+} \mathrm{SIGLEC6}^{+} \mathrm{DCs}\right)$ and DC6 (pDCs). DC1 represent the cross-presenting $\mathrm{CD} 141^{+} / \mathrm{BDCA}^{+}$DCs while D2 and D3 correspond to $\mathrm{CDCs}$ displaying antigen uptake and processing capabilities. DC4 seem to be more prone to respond to viruses and are phenotypically close to monocytes. DC5 represent a newly defined subset that share features with both pDCs and cDCs, even though they appear to be functionally different from $\mathrm{pDCs}$ and more similar to cDCs. Indeed, DC5 localize in $\mathrm{T}$ cell zone of tonsils, probably promoting fast adaptive immunity. Due to this fine clustering, DC6 correspond to a more pure pDCs population (12). This precise classification opens the way for a more accurate view of DCs role in pathologies and provides cues for more specific targeting in immunotherapies. Indeed, it is reasonable to assume that this extreme phenotypical diversity correlates with different intrinsic functional properties of DCs, as emerged in Villani's work $(12,17,18)$. In addition, environmental cues dictate DC activation and drive specific T cell responses $(19,20)$. Indeed, DCs display a plethora of pattern recognition receptors (PRR) that are specifically bound by microbe- or damage-associated molecular pattern (PAMP and DAMP, respectively) (21). Upon receptors engagement in peripheral tissues, the transduction signals lead to DC maturation with the upregulation of co-stimulatory molecules
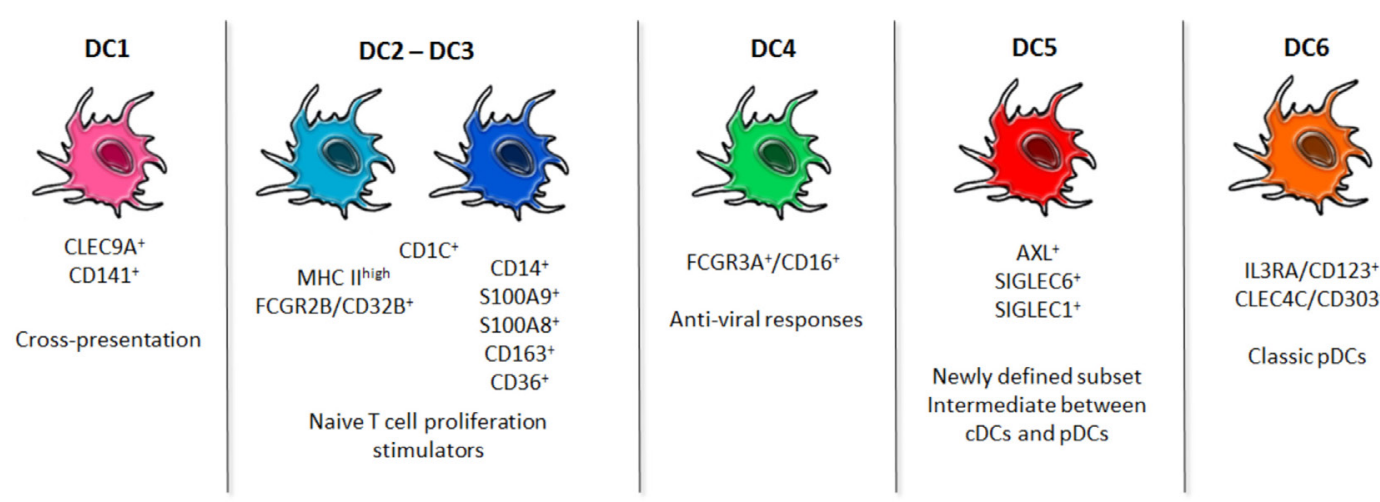

IL3RA/CD123+

$\mathrm{CLEC4C/CD303+}$

ClassicpDCs

FIGURE 1 | Dendritic cells (DCs) readapted taxonomy. Newly identified populations of blood human DCs are shown. DC1 subset is clearly distinct by the expression of CLEC9A, and it is specialized in cross-presentation of ags. DC2 and DC3 constitute the conventional DCs pool, even though they appear to be phenotypically slightly different and, upon stimulation with TLR ligands, their diversity emerges. DC4 is a population characterized by an upregulated Type I Interferon pathway for antiviral responses. DC5 has emerged as a new population whose specific functions are still unexplored. DC6 corresponds to the classic plasmacytoid DCs. These advances in the fine characterization of DCs in humans may shed light on the best subset to be targeted to incentivize the desired immune response. 
(referred to as "signal 2") and the pivotal chemokine receptor CCR7 that allows DCs migration through afferent lymphatic vessels to the draining lymph node (LN) (22-24). In parallel, DCs mediate ag proteolysis to present intracellular peptides on major histocompatibility complex (MHC) class I to CD8 ${ }^{+} \mathrm{T}$ cells and exogenous peptides on MHC II to $\mathrm{CD}^{+} \mathrm{T}$ cells (referred as "signal 1"). DCs can present exogenous ags on MHC class I through the so-called cross-presentation, allowing them to induce $\mathrm{CD}^{+}$cytotoxic T lymphocytes (CTLs) against viruses and tumor cells. Indeed, once in the LN, mature DCs encounter cognate naïve $\mathrm{T}$ cells and initiate adaptive responses (25). In the absence of maturation, as in steady-state conditions, the ag presentation and consequent migration to $\mathrm{LN}$ promote peripheral tolerance via $\mathrm{T}$ cell anergy or regulatory $\mathrm{T}$ cell formation (26-28). Depending on the receptors engaged, DCs display different maturation states and produce different inflammatory mediators (often referred to as "signal 3") that impact on the following cellular and humoral responses. The three signals released by DCs drive T helper (Th) cell differentiation. Briefly, DCs educate $\mathrm{CD}^{+} \mathrm{T}$ cells against intracellular bacteria by promoting their polarization into IFN- $\boldsymbol{\gamma}$-producing Th type 1 (Th1) cells. Upon infection by multicellular parasites, DCs, with the help of basophils, polarize CD4 ${ }^{+}$T cells into Th type 2 (Th2) cells that produce mainly IL-4. For specialized mucosal and skin immunity, DCs drive the activation of Th type 17 (Th17) (29). Thus, polarization of T cells is a crucial event that provides mechanisms specifically orchestrated to restore physiological homeostasis. DCs undergo apoptosis once they have fulfilled their functions. The rapid DC turnover after activation is necessary to avoid excessive T cell activation (30) and to maintain self-tolerance $(31,32)$. T lymphocyte activation culminates with the establishment of the immunological memory, providing the host with $\mathrm{T}$ cells more prone and efficient in responding to a reinfection by the same pathogen or upon tumor relapses (33). Besides, DCs are key players in humoral responses too. Indeed, they directly interact with B cells and indirectly support them by activating $\mathrm{CD} 4^{+} \mathrm{T}$ cells, leading to humoral memory. All these notions strengthen the idea that DCs represent an optimal target for immunotherapies and vaccines, acting at the interface of innate and adaptive immunity.

\section{ADJUVANTS SHAPING DC FUNCTIONS}

To harness robust responses through DC-targeting vaccinations, DC maturation is essential. Adjuvants become compulsory complement of inactivated or subunit vaccines that may promote suboptimal responses. Furthermore, they improve DC migration, ag availability, and specific targeting. Although it seems clear that immunization could benefit from adjuvant uses, the solely adjuvant licensed in clinics, until recently, was alum (34). Despite alum has been used in vaccination practice since the beginning of the last century, the mechanism through which it activates innate immunity for the subsequent activation of adaptive immune responses remains elusive. The adjuvant properties of alum were initially attributed to the activation of NLRP3 inflammasome $(35,36)$; nevertheless, further studies have clearly shown the dispensability of NLRP3 and caspase-1 for the generation of responses in the presence of this adjuvant $(37,38)$. TLR signaling is also dispensable for alum adjuvanticity (39) as well as mast cells, eosinophils, or macrophages (40). Recently, it has been proposed that upon contact with alum, DCs produce IL-2 through the activation of src and Syk kinases, $\mathrm{Ca}^{2+}$ mobilization, and NFAT nuclear translocation. IL-2, in turn, is required for optimal $\mathrm{T}$ cell priming, activation, and antibody production (41). In addition to alum, other chemical adjuvants have been tested in preclinical models, showing a clear heterogeneity in the responses driven by different adjuvants, independently of the ag (42). This underlies the need of deepening our knowledge on these powerful tools to drive immune responses. Indeed, MF59, an oil-in-water emulsion adjuvant, that allows long-lasting ag retention in draining $\mathrm{LN}$ and enhanced ag uptake by LN-resident DCs, promotes robust humoral responses via follicular DC activation (43) and $\mathrm{CD}^{+} \mathrm{T}$ cell immunity induction (44). Conversely, IC31 adjuvant, which consists of an antibacterial peptide and a synthetic oligodeoxynucleotide (ODN), elicits IFN- $\beta$ release by human DCs via engagement of endosomal TLRs supporting immunity against intracellular pathogens and cancer (45).

In the last decades, attention has been focused on TLR ligands as adjuvants. Currently, several compounds are under investigation: Pam2CSK4, Pam3CSK4, or analogs as TLR2/6 or TLR2/1 ligands $(46,47)$, Poly(I:C) and similar compound acting on TLR3 $(48,49)$, TLR4 agonists (50), Flagellin acting on TLR5 (51), Imiquimod and other TLR7 ligands (52, 53), TLR8 agonists (54), CpG ODN binding TLR9 $(55,56)$. Due to the possible reactogenicity that may be induced by administering TLR agonists, some compounds are chemically modified to reduce toxicity or are delivered specifically to the DC subsets of interest, avoiding TLR ligand dissemination. Monophosphoryl lipid A, a low-toxicity molecule derived from lipopolysaccharide (LPS), displays promising effects for vaccine design (57) even though it promotes terminal differentiation of $\mathrm{CD}^{+}$cells, leading to reduced memory protection (58). Another LPS-analog is 7-acyl lipid A that has emerged as potent inducer of IFN- $\boldsymbol{\gamma}$-mediated ag-specific responses when co-delivered with poorly immunogenic tumor ags (59).

To improve the effectiveness and strength of immunity, in addition to the efficiency of APC, activation and ag processing and presentation of other aspects should be taken into account. The importance of DC-derived IL-2 in the activation of adaptive responses has been shown not only in alum-driven immune responses and in mouse models of infections $(60,61)$ but also in tests of human $\mathrm{T}$ cell priming in the presence of activatory DCs. During the first few hours after interaction with $\mathrm{T}$ cells, activatory monocyte-derived DCs (MoDCs stimulated with the cytokine cocktail, TNF- $\alpha$, IL- 6 , IL- $1 \beta$, and $\mathrm{PGE}_{2}$ ) produce IL-2 and CD25 (62). DC-derived IL-2 is, in turn, trans-presented to $\mathrm{T}$ cells at the immunological synapse via CD25. Since naïve $\mathrm{T}$ cells start to express CD25 only many hours after ag encounter, the DC-mediated presentation of the IL-2/CD25 complex is indispensable for an efficient $\mathrm{T}$ cell priming (62). It has been proposed that this is the reason why approved therapies based on the use of anti-CD25 antibodies to avoid the acute phases of autoimmune diseases, or acute rejection of kidney, heart, and 
hand transplants, are so efficient in interfering with $\mathrm{T}$ cell priming or T cell reactivation (62). Since IL-2 is produced in NFATdependent manner to improve the adjuvanticity of PRR agonists for vaccination purposes, the capacity of selected PRR agonists to induce NFAT signaling pathway activation and IL-2 production should be considered. Many PRR ligands have been shown to activate the NFAT transcription factor family members in innate immune cells (63). The NFAT pathway is activated in neutrophils, macrophages, and DCs in response to curdlan $(64,65)$, it is also activated in DCs in response to LPS (30) downstream of CD14, it is activated in response to mannose-capped lipoarabinomannan (Man-LAM), a major lipoglican of Mycobacterium tuberculosis (66), and downstream of TLR9 in response to $\beta$-glucan bearing fungi (67). The production of IL- 2 by innate immune cells during inflammatory responses is relevant not only for an efficient $\mathrm{T}$ cell priming but also for the skewing of $\mathrm{T}$ cell activation toward type I responses. In mice, DC-derived IL-2 is one of the cytokines required to elicit IFN- $\gamma$ production from NK cells both in LPSmediated inflammatory conditions and during fungal infections (68-70). IFN- $\gamma$ potently activates macrophages and favors Th1 commitment of $\mathrm{CD}^{+} \mathrm{T}$ cells. Therefore, early IFN $-\gamma$ release by NK cells is not only crucial for controlling a variety of primary bacterial and fungal infections but also for the induction of type I immunity and memory, fundamental for the protection against bacterial, fungal, and viral infections and in antitumor immune therapies.

Another important reason for considering the capacity to activate the NFAT pathway in adjuvant selection tests is represented by the fact that NFATs regulate also the production of the prostanoid $\mathrm{PGE}_{2}$ by activated DCs (71). $\mathrm{PGE}_{2}$ promotes activated DC migration (72) and sustains vasodilation and local edema formation during the inflammatory process. This is particularly relevant for vaccination purposes since the increase of the interstitial pressure generated by the edema forces the fluids into the afferent lymphatics and favors a first wave of antigen arrival to the draining LN (71). Intriguingly, LN drainage of proteins or antigens occurs very rapidly after subcutaneous, intradermal, and intramuscular immunization (73-75), thus permitting an extremely fast uptake by phagocytes strategically localized in close proximity to the subcapsular sinus or lymphatic sinus of draining LN (76-79).

Antigen-presenting cells in LN then maintain the homeostasis of LN themselves and activate adaptive immune responses. In the last decades, the long-held paradigm of migratory DCs, resident in peripheral tissues as the skin, as unique APCs involved in T cell immunity has dramatically changed. Indeed, CD169+ subcapsular sinus macrophages, medullary macrophages, and LN-resident DCs are LN sentinels that avoid excessive pathogen dissemination $(80,81)$ and mediators of immune responses $(76)$.

Concerning migratory DCs and considering the skin, which represents the site of utmost importance for vaccination strategies due to the ease accessibility and the extremely high presence of DCs, skin-resident DCs have been subdivided into epidermalresident Langerhans cells (LCs), which are Langerin ${ }^{+}$and two diverse subsets of dermal (d)DCs: Langerin ${ }^{+} \mathrm{CD} 103^{+}$and Langerin $^{-} \mathrm{CD}^{-103^{-}}(14,82)$. Upon infection, dDCs migrate to the LN within 10-24 h while LCs within 48-72 h, supporting long-lasting ag-presentation. Several works reveal the intrinsic differences between the two subsets in inducing Th or CTL responses, due to the particular cross-presenting capabilities of $\mathrm{CD}_{103^{+}} \mathrm{dDC}$, for instance $(19,20,83)$. Once in the LN, whose strategical architecture enhances the probability of encounter between migratory DCs and cognate naïve $\mathrm{T}$ cell, adaptive immunity is initiated. Of note, LN-resident DCs are sufficient to promote early adaptive responses independently of migratory DCs when pathogens or antigens directly access the lymphatic conduits $(76,84,85)$. In antiviral responses, CD $8 \alpha^{+} \mathrm{LN}$-resident DCs play a crucial role, thanks to their intrinsic capability of cross-presentation to $\mathrm{CD}^{+} \mathrm{CTL}(86,87)$ that may be supported by pDCs (88). In Herpes Simplex Virus (HSV) skin infection, CD $8 \alpha^{+} \mathrm{LN}$-resident DCs uptake cargo-antigens, ferried by skinresident migratory DCs in order to elicit CTL (89). Indeed, LCs and dDCs synergize with CD $8 \alpha^{+} \mathrm{LN}$-resident DCs, which stand out as the most potent CTL inducers, preferentially sustaining $\mathrm{CD}^{+}$Th responses both in influenza (90) and HSV cutaneous infections (91). In addition to CD $8 \alpha^{+} \mathrm{LN}$-resident DCs, CD103 ${ }^{+}$ dDCs display intrinsic capability of cross-presentation, as their human counterpart, CLEC9A ${ }^{+}$CD141+ DCs (92-96). Besides, some authors demonstrated that blocking DC migration from the skin hinders $\mathrm{CD} 4^{+} \mathrm{T}$ cell activation in response to subcutaneous bacterial (97) or soluble antigen challenge (98). Ablating Langerin $^{+}$dDCs reduced $\mathrm{T}$ cell immunity strength, corroborating the notion that migratory DC complement LN-resident DC effects on adaptive responses (99-101). Nonetheless, the roles of LCs in activating T cells are still uncertain, probably due to the controversial functional properties of this innate subset (102104). Despite this, the synergic effects of LN resident and migratory DCs seem to be undoubted $(25,105)$. Indeed, Allenspach and colleagues reported that ag presentation by LN-resident DCs few hours after the infection is required to entrap ag-specific $\mathrm{T}$ cells in the draining $\mathrm{LN}$ and to favor an optimal activation of $\mathrm{T}$ cells by migratory DCs that arrive at the LN many hours later (106).

It emerges, therefore, that another aspect to be considered for the identification of efficacious adjuvants concerns the type of DC subset to be targeted and the consequential effects that adjuvants imprint on that subset. Adjuvants play a pivotal role in determining tissue-resident DC mobility to draining LN and efficiency of $\mathrm{T}$ cell polarization. Indeed, dDCs acquire mobility after subcutaneous injection of Th1-specific adjuvants as $\mathrm{CpG}$ and LPS, but not with Th2-specific ones, as papain, or following contact sensitization with dibutyl phthalate and acetone. Moreover, dDCs are sufficient to promote Th 1 and Th 2 responses, while LCs are only supportive of Th1 (107). This evidence underscore that, in addition to the polarizing capabilities of adjuvants, also the targeted DC subset must be considered to elicit specific adaptive immunity. Indeed, Antonialli and colleagues reported differential immune responses when $\mathrm{CD} 8 \alpha^{+}$and $\mathrm{CD} 8 \alpha^{-} \mathrm{DCs}$ were targeted with the same ag and adjuvant, either CpG ODN or Flagellin (108).

In addition, to enhance the efficacy of vaccination, the coincident delivery of ag and PRR adjuvants to APCs plays a crucial role. Encouraging evidence highlights the importance of conjugation of ag with PRR adjuvants, since it improves ag uptake, humoral 
and cellular responses when compared to vaccination with ag codelivered with free TLR ligands (109). These findings strengthen the notion that adjuvants are formidable chiefs in shaping immune responses and must be selected for the outcomes they promote, in chemical association to the ag of interest.

\section{NOVEL STRATEGIES OF VACCINATION: MULTITASKING CARRIERS}

The traditional vaccination approaches consisted in the administration of live or attenuated micro-organisms. Up to now, several innovative strategies have emerged to address the need for efficient vaccines, especially against diseases that are critical to treat, as cancer and the infectious diseases already mentioned. The main purpose is to convey ag, adjuvant, and targeting-molecule in a unique compound to increase the efficacy of the ag-specific immune response. To address this issue, different approaches have been explored or are currently under investigation, as shown in Figure 2.

Recombinant antibody ( $\mathrm{rAb})$ represents a feasible option. This approach exploits the possibility to chemically fuse peptide ag, adjuvant, and targeting-molecule to $\mathrm{Ab}$ to tailor $\mathrm{DCs}$ targeting (110-112). In addition to $\mathrm{rAb}$, single-chain fragments variable $(\mathrm{scFv})$ revealed to be an appealing strategy due to their reduced size and enhanced infiltration into tissues, as in solid tumors (113).

Other approaches involve the use of nano-carries as vehicles. The most promising solution to target phagocytes is indeed the use of particulate materials $(114,115)$. Nanoparticles (NPs) are the best candidates as delivery system, since they can be manipulated to efficiently and predominantly target phagocytes. This is possible, thanks to the versatility of NPs due to: (i) the large amounts of existing different nanomaterials; (ii) the possibility to adjust their size, morphology, and deformability with great precision; (iii) the possibility to load virtually any different type of drug molecules (116).
Viral vectors-based vaccines or virus-like particles rely on the intrinsic capability of viruses to infect cells and exploit their protein-encoding machinery, allowing expression in the cytosol of the engineered plasmid-genes, as ag, costimulatory molecules, cytokines, and adjuvants, providing the bases for strong CTL induction (117). On the other hand, naked DNA can be directly injected or conjugated to nano-carriers to favor specific targeting. The easy designing of nano-carriers-based vaccines along with their multi-component loading feature improve targeting of specific subsets (118) and shape immune responses $(119,120)$, favoring their application in several fields. In a cancer setting, nano-carriers allow to avoid killing of healthy cells, by delivering tumor ags or DNA encoding these peptides to APCs, inducing specific antitumor responses. Indeed, NPs allow endocytosis and MHC presentation on both class I and II (121) eliciting broad adaptive immunity, even against cancer cells. Rosalia and colleagues designed a polymer-based biodegradable poly(lactic-co-glycolic acid) PLGA NPs loaded with ag, Pam3CSK4, and Poly(I:C) and coated with an agonistic $\alpha \mathrm{CD} 40$-monoclonal Ab (NP-CD40). This multi-functional strategy resulted in efficient and selective delivery of NPs to DCs in vivo upon s.c. injection and induced priming of $\mathrm{CD}^{+} \mathrm{T}$ cells against tumor associated ags, increasing tumor-bearing mice survival (109). PLGA NPs carrying the poorly immunogenic melanoma-derived antigen tyrosinase-related protein 2 along with 7-acyl lipid A, manage in breaking the immunotolerance acting against tumor-antigens. Indeed, administration of the abovementioned NPs resulted in antigen-specific $\mathrm{CD} 8^{+} \mathrm{CTL}$ responses, characterized by IFN- $\gamma$ production and increase of pro-inflammatory cytokines in the tumor microenvironment (TME) (59). Another nano-carrier-based approach relies on liposome, self-assembled vesicles composed by lipid bilayers with high functionalizing properties. Besides, Maji and colleagues reported that after uptake by DCs, cationic liposomes localize in endosomal compartments that allow ag presentation preferentially on MHC I but do not exclude MHC II ag
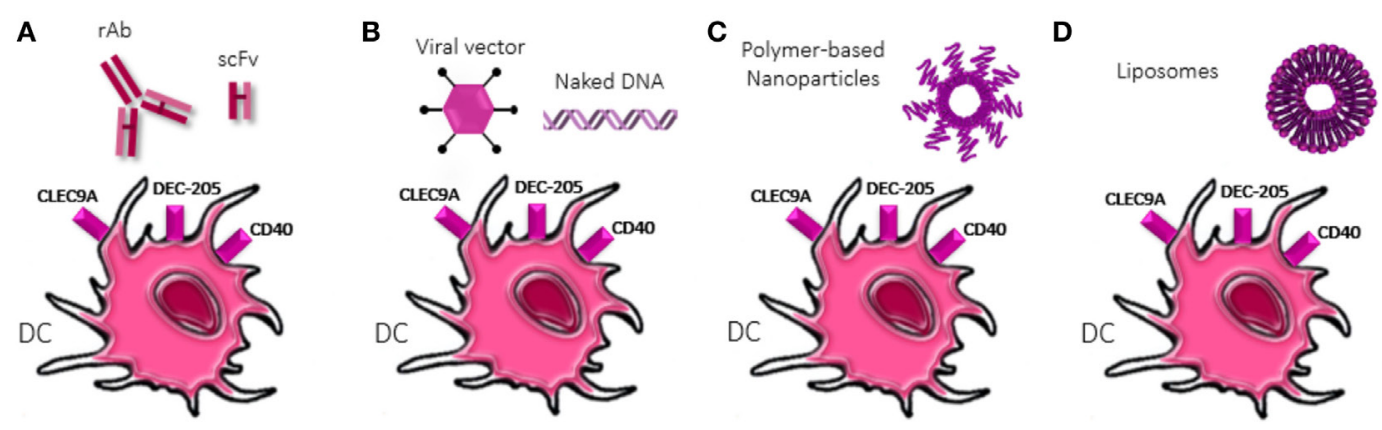

FIGURE 2 | Strategies of dendritic cells (DCs) targeting. Diverse approaches to deliver antigens to DCs are shown. (A) Recombinant antibody or single-chain variable fragment (scFv) specific for DC receptors are chemically conjugated with antigen and adjuvant molecules. scFv reduced dimension confers them higher tissue-penetrating properties. (B) Viral vector-based vaccines or naked DNA exploit the encoding machinery of DCs to translate antigens, adjuvants but also co-stimulatory molecules ("signal 2") and cytokines ("signal 3") increasing the activatory profile of DCs. Naked DNA could be delivered conjugated to nanoparticles (NPs) and liposomes. (C) Polymer-based NPs display physical and chemical properties that allow encapsulation or conjugation of antigens and adjuvants as well as ligands for specific DC receptors. Different polymer compositions provide diverse properties and dimension, allowing easy diffusion and/or retention in lymph node. (D) Liposomes allow both the encapsulation and intercalation in the phospholipid bilayer of antigens and adjuvants, depending on their chemical properties, as well as the functionalization of the surface with ligands of DC receptors. 
presentation (122), suggesting a crucial role in antitumor or antiviral immunity supported by Th responses.

In addition to the use of NPs, targeting DC-specific receptors has become an attractive strategy for vaccine development due to the enforced efficiency of immune responses when compared to generic-delivering approaches. Here, we report the more characterized DCs receptors, currently under investigation in the scenario of tailored-vaccination, as shown in Table $\mathbf{1 .}$

CLEC9A or DNGR1 is a C-type lectin receptor that mediates endocytosis, but not phagocytosis, with low $\mathrm{pH}$ endosomes promoting the drift toward cross-presentation. Importantly, CLEC9A binding of antigens induces antigen presentation on both MHC I (cross-presentation) and MHC II. It is highly and specifically expressed on $\mathrm{CD} 11 \mathrm{c}^{+} \mathrm{CD} 141^{+} \mathrm{XCR} 1^{+} \mathrm{CDCs}$ and $\mathrm{CD} 14^{+} \mathrm{CD} 16^{-}$monocytes in human and in murine $\mathrm{pDCs}$ and $\mathrm{XCR}^{+}{ }^{+} \mathrm{CD} 8 \mathrm{a}^{+} \mathrm{LN}$ resident but not $\mathrm{CD} 103^{+} \mathrm{XCR} 1^{+}$migrating $\mathrm{DCs}$ $(123,124)$. Indeed, $\mathrm{CD} 141^{+} \mathrm{XCR} 1^{+} \mathrm{DCs}$ constitute the human counterpart of $\mathrm{CD} 8 \alpha^{+} \mathrm{XCR} 1^{+}$murine DCs (125). They share $\mathrm{XCR} 1$, the receptor of XCL1. XCL1 is released by activated T cells and the axis XCR1-XCL1 is necessary for robust CTL responses (126). $\mathrm{CD} 141^{+} \mathrm{XCR} 1^{+} \mathrm{DCs}$ are the main cross-presenting DCs in human, thus they appear promising for CTL-mediated responses, in tumors and viral infections (127). This specific subset is characterized by the expression of TLR3 that may be exploited to fully activate CLEC9A ${ }^{+} \mathrm{XCR}^{+}{ }^{+} \mathrm{DCs}$ since antibody binding of CLEC9A leads to its rapid internalization but not TLR-pathway activation, preventing pro-inflammatory cytokine production and full maturation of DCs (127). Conversely, Caminschi and $\mathrm{Li}$ independently demonstrated the potentiality of targeting Clec9A that resulted in enhanced humoral immunity independently of TRIF-MyD88 or TLR4 pathway, even in the absence of adjuvants $(128,129)$. Targeting Clec9A induces enhanced $\mathrm{CD}^{+}{ }^{+} \mathrm{T}$ cell proliferation in vivo, which supports B cell immunity, when compared to the targeting of another endocytic receptor, discussed later, DEC-205, independently of the use of adjuvants as CpG (130). Some years later, different authors demonstrated that this strong humoral response is endorsed by the establishment of follicular $\mathrm{T}$ helper cells memory, even upon vaccination with glycoprotein D of HSV, both in mice and non-human primates $(128,131,132)$. These promising results were confirmed also in a human in vitro setting, on CD $141^{+} \mathrm{DCs}$ (133). Finally, the efficacy of targeting Clec9A has been evaluated in the delivery of poorly immunogenic virus-derived antigens. Park and colleagues managed in conferring specific humoral response, protective upon reinfection (134). Thus, exploiting the specific expression of this receptor on the most specialized DCs in cross-presentation in combination with TLR3 ligands, will enhance antiviral and anticancer responses (135), combined with robust humoral immunity.

DEC-205 or CD205 is a $205 \mathrm{kDa}$ endocytic receptor that has a cysteine-rich domain, a fibronectin type II domain, and $10 \mathrm{C}$-type lectin-like domains, as well as an internalization sequence in its cytoplasmic tail (136). Thus, it mediates cross-presentation through clathrin- and dynamin-dependent receptor-mediated endocytosis. Indeed, it is expressed by the most professional cross-presenting DCs, the CD $8 \alpha^{+}$DCs subtype, while $\mathrm{CD} 8 \alpha^{-} \mathrm{DCs}$ display very low level of this receptor. In addition, DEC-205 is found on dermal/interstitial DCs and LCs (137), thus guaranteeing ag delivery to both skin-resident and LN-resident professional APCs. In humans, DEC-205 is shared among cDCs, monocytes, and B cells, while pDCs, granulocytes, NK cells, and T lymphocytes express low levels of this receptor (138). In addition, DEC-205 regulates molecule recycling through late endosomes, promoting also MHC II presentation to $\mathrm{CD}^{+} \mathrm{T}$ cells in LCs (139). Steinman and Nussenzweig have addressed this molecule to improve vaccine efficacy since 2000 (140). By taking advantage of anti-DEC-205 $\mathrm{rAb}$ conjugated to OVA peptide, they demonstrated that s.c. injections of this compound lead to a strong IFN- $\gamma$ and IL-2mediated immunity only when DCs activation was supported by $\alpha \mathrm{CD} 40 \mathrm{mAb}$, otherwise, tolerance against the OVA peptide occurs (141). Indeed, diversely from PRR agonists, antibody crosslinking the DEC-205 does not induce DCs maturation (142). Furthermore, few years later, the combined strategy of anti-DEC-205 and $\alpha$ CD40 was reported to confer protection against melanoma and intranasal influenza infection (112).

TABLE 1 | Targeted receptors for tailored ags delivery.

\begin{tabular}{|c|c|c|c|c|}
\hline & Receptor & Expression & Activity & Clinical trials \\
\hline DEC-205 & Endocytic receptor & $\begin{array}{l}\text { Human: cDCs, monocytes, B cells } \\
\text { MOUSE: CD } 8 \alpha^{+} \text {DCs } \\
\text { Dermal/interstitial DCs } \\
\text { Langerhans cells }\end{array}$ & $\begin{array}{l}\text { MHC class I } \\
\text { MHC class II } \\
\text { Ag presentation }\end{array}$ & $\begin{array}{l}\text { NCT03358719: recruiting } \\
\text { NCT01834248: completed } \\
\text { NCT02166905: recruiting } \\
\text { NCT01522820: completed }\end{array}$ \\
\hline CD40 & $\begin{array}{l}\text { Transmembrane glycoprotein } \\
\text { Surface receptor }\end{array}$ & $\begin{array}{l}\text { Human/mouse: cDCs and pDCs, monocytes, B cells, } \\
\text { endothelial cells }\end{array}$ & DCs activation & $\begin{array}{l}\text { NCT03329950: recruitinga } \\
\text { NCT02706353: recruiting } \\
\text { NCT03214250: recruiting } \\
\text { NCT03389802: recruiting } \\
\text { NCT03418480: recruiting } \\
\text { NCT03123783: recruiting }\end{array}$ \\
\hline
\end{tabular}

aThere are currently more than 30 clinical trials involving the anti-CD40 antibody. Here, the more recent trials regarding DCs-based vaccination strategies are reported. 
In a viral setting, anti-DEC-205 rAb chemically coupled with HIV p24 gag protein tested in vitro on blood cells derived by $11 \mathrm{HIV}$-infected donors has revealed efficient expansion of IFN- $\gamma$-producing CD8 ${ }^{+} \mathrm{T}$ lymphocytes (143) from all the different donors. This indicated that DCs and CD205 can lead to the generation of different peptides from a single protein. Moreover, vaccines based on the filamentous bacteriophage fd presenting an $\alpha \mathrm{DEC}-205 \mathrm{scFv}$, efficiently induce DCs maturation via the activation of the TLR9-MyD88 pathway (144), without adjuvants and further elicit potent antitumor responses when compared to non-tailored ag delivery (145). Intriguingly, DEC-205, orphan of a specific ligand, has been proven to be necessary for CpG uptake and eventual DC activation (146).

CD40 is a molecule belonging to the TNF receptor family, expressed by several cell types and among these, DCs. It has emerged as a receptor for the human chaperone Heat shock protein (Hsp) 70 that mediates the internalization of peptides bound to Hsp70 itself (147). Moreover, upon activation, T cell transiently expresses CD40L allowing cross-linking of CD40 on DCs and completing their maturation. From these notions, CD40 appeared an interesting molecule to target for DC-based vaccination strategies. Indeed, by engineering antibody chemical structure, Schjetne and colleagues demonstrated the efficacy of CD40 engagement conferring protection against myeloma- and lymphoma-derived ags (148). Moreover, through the co-administration of two DNA-based vaccines encoding either CD40 and the foot-and-mouth disease-derived ags, the transient increase of endogenous $\alpha \mathrm{CD} 40$ antibodies allows an efficacious DCs activation and an efficient development of ag-specific $\mathrm{T}$ cell immunity, if compared to the administration of DNA encoding ags alone (149). Further promising results have been obtained in a vaccine against cyclin-D1 that is overexpressed by mantle cell lymphoma (MCL). Thanks to algorithm analysis, Chen and colleagues identified three cyclinD1-derived peptides that efficiently bind to MHC class I of DCs, potentially overexpressed in all MCL patients. By generating a $\mathrm{rAb}$ targeting CD40, they efficiently delivered these tumor associated ags to DCs and mounted IFN- $\gamma$-specific T cell responses in patients-derived peripheral blood mononuclear cells (150). Thus, CD40 represents a specific DC-targeting molecule that has been used in combination with other targeting approaches to support specific DCs activation, avoid tolerance, and induce robust $\mathrm{T}$ cell immunity $(110,141)$.

\section{DCs AND CANCER}

When evaluating vaccination strategies for cancer patients, it is compulsory to take into account one of the hallmarks of cancer: avoiding immune destruction by promoting tolerance and disarming the immune system (5). The orchestration of antitumor responses involves multiple protagonists and mediators, among these, cytotoxic T cells and NK cells, whose activation is supported by DCs (151). Furthermore, DCs-based vaccines has emerged as more efficient in promoting $\mathrm{T}$ cell immunity if compared to peptide-based vaccination approaches (152). Thus, much effort has been made to improve strategies of DCs-based vaccination in neoplastic diseases, to ameliorate the prognosis or eradicate both primary tumor and metastases. Up to now, two different approaches have been addressed: ex vivo generation of autologous pulsed DCs and direct in vivo targeting of DCs, as previously discussed. The former strategy provides a better control of the maturation and activation state of DCs and a specific load of the ag to the selected DCs subset. Despite this, intense work is needed to generate this vaccine, since it is personalized for each patient and only few subsets of DCs are feasibly generated in vitro or collected ex vivo, limiting the access of ags to other more functionally driven subsets. Diversely, the in vivo targeting methods allow the generation of large amount of vaccine in a one-step procedure, and the targeting of diverse DCs subsets in their natural environment.

Once the DCs-based vaccine is generated, the efficacy of antitumoral responses has to be evaluated. It is mainly related to (i) the capability to establish specific antitumor-associated ag (TAA) immunity and (ii) the overcome of the tolerogenic status promoted by the TME.

To select highly immunogenic ags, multiple solutions have been tested: whole tumor lysate or killed tumor cells, synthetic long peptides (SLPs), full length proteins, transfection or electroporation with DNA or mRNA coding for TAA, transduction with lentiviral vectors and neoantigens. The availability of an elevated number of antigens through the incubation of DCs with whole tumor lysates or autologous tumor cells allows the presentation of multiple epitopes, loaded on both MHC class I or II, which leads to Th and cytotoxic responses. Indeed, several clinical trials are currently evaluating the benefits obtained by using this approach (NCT01875653; NCT00045968; NCT02496520). SLPs are 28-35 aa long peptides cross-presented by DCs (153), currently under investigation in both preclinical and clinical setting. Compared to short synthetic peptides, the use of SLPs lacks the necessity to know the patients' HLA haplotype, thus permitting their full exploitation in a larger cohort of people. Moreover, SLPs administration to DCs leads to an enhanced $\mathrm{CD}^{+} \mathrm{T}$ cells activation since, once engulfed, they rapidly escape from the endolysosome to follow the path of MHC class I presentation, fundamental in antitumor responses. Indeed, SLPs and DCs-based vaccines are showing promising results in terms of safety and immunogenicity, in both preclinical and clinical settings (154). They have gained attention in the context of human papilloma virus cervical (155), ovarian (156), and colorectal cancer $(157,158)$, displaying immunogenic capacities, in terms of antibody production and $\mathrm{CD}^{+}$and $\mathrm{CD}^{+} \mathrm{T}$ cell activation, when delivered with adjuvants, as poly ICLC, Montanide-ISA-51 (NCT02334735), and IFN $\alpha$. When comparing SLPs and full length proteins, it has emerged that DCs process SLPs better that full length protein, due to the slower processing route the latter display (154). Concerning transfection or electroporation of DCs with mRNA or DNA encoding, not only for TAA but also for costimulatory molecules and cytokines, to enforce adaptive immunity, has proven to be efficacious in inducing antitumor $\mathrm{CD}^{+}$and $\mathrm{CD}^{+} \mathrm{T}$ cells expansion, mediated by DCs targeting (159). A similar approach regards in vivo lentiviral transduction of DCs, which displays versatility for gene delivery and efficient transduction for non-dividing cells, as DCs. Indeed, Bryson et al. conceived a multifunctional vaccine 
composed by a modified lentivirus, whose glycoproteins can directly target DC-SIGN on DCs, loaded with breast cancer ags, alpha lactalbumin, and erb-b2 receptor tyrosine kinase 2. Single injections of the compound provided tumor self-ags-specific $\mathrm{CD}^{+} \mathrm{T}$ cell immunity, reducing tumor growth (160). Despite the improvements derived by these advanced strategies, in the last years, neoantigens are becoming more and more appealing (161). During tumor progression, cancer cells give rise to neoantigens, novel ags different from the self-tumor ags, derived by the tumor-specific mutations. Therefore, prediction tools, RNA mutanome, and deep-sequencing have allowed the identification of specific non-self-ags that are fundamental in strong $\mathrm{T}$ cell immunity (162-164). Indeed, several clinical trials are currently investigating the potential of neoantigens (NCT0235956; NCT01970358; NCT02149225; NCT02348320; NCT02316457). As emerged, different strategies of ags selection have been explored and, even though one strategy may result in a more enforced antitumor immunity if compared to another, still the issue of the TME negative influence on the immune system has to be faced. Indeed, the TME actively suppresses the activation of the immune system. Tumor cells secrete immunosuppressive cytokines, as vascular endothelial growth factor $(165,166)$, macrophage colony-stimulating factor (167), transforming growth factor $\beta$ (TGF- $\beta$ ) (168), and IL-10 $(169,170)$. Even though some of these cytokine display controversial roles, depending on the pathological context, they generally promote DCs tolerogenicity, by limiting their activation and increasing their expression of pro-tumor molecules, such as programmed cell death 1 (PD-1) and indoleamine 2,3-dioxygenase (IDO). Therefore, tolerogenic DCs lead to T cells anergy, Tregs expansion, and Th1 responses inhibition. Phenotypical characterization of immune cells isolated from breast cancer patients, highlighted the functional alteration in DCs, T, and NK cells in promoting antitumor responses (171). Furthermore, tumor cells retain DCs into the TME, preventing their migration to draining LNs and promoting metastatization (172). To address this issue, some ex vivo generated DCs-based vaccines are directly administered intranodally, as for the CD1c ${ }^{+}$DCs pulsed with HLA-A2.1-restricted tumor peptides administered to patients with stage IV melanoma (NCT01690377), which generated tumor-specific CD8 ${ }^{+} \mathrm{T}$ cells responses and further improvement of survival (173). To reduce the tolerogenic influence of the TME on DCs, the positive role of GM-CSF in improving DCs survival and responsiveness is currently exploited in some clinical trials like a phase I/II trial with a DC/tumor cell fusion vaccine administered in association with GM-CSF to treat renal cancer (NCT00458536). Similarly, others are focusing their attention on FMS-like tyrosine kinase 3-ligand (FLT3L), another crucial DCs growth factor, in combination with other compounds (NCT01811992; NCT01976585; NCT02129075; NCT02839265). FLT3L has, indeed, been shown to increase the efficacy of proteins- and RNA-based vaccines, due to a maturation effect on DCs (174-176). Additional efforts made to counteract the tolerogenic influence of the TME include the use of PD-1 and IDO inhibitors. Co-administration of antiPD-1 molecules increases the efficacy of DCs-based vaccines, in terms of enforced intratumoral $\mathrm{CD}^{+} \mathrm{T}$ cell responses and trafficking of $\mathrm{CD}^{+}$memory $\mathrm{T}$ cells, as observed in a preclinical model of glioblastoma (177). In parallel, several clinical trials are aiming at evaluating the efficacy of DCs-based vaccines combined with anti-PD-1 agents (NCT03014804; NCT03325101; NCT03035331). The other tolerogenic marker addressed in cancer immunotherapy and DCs-based vaccine is IDO. Indeed, silencing approaches to reduce the expression of IDO in DCs for vaccination in preclinical models, have resulted in decreased $\mathrm{T}$ cell apoptosis, reduced numbers of Tregs, decreased tumor size when compared to mice that had received ags-loaded DCs without IDO silencing (178). IDO inhibitors in DCs vaccination are currently being tested in phase II clinical trials (NCT01560923; NCT01042535).

All these approaches have explored different scenarios to evaluate the more efficient therapeutic combination that seems to move toward personalized vaccinations for cancer patients.

\section{CONCLUDING REMARKS}

In this review, we have underscored the crucial role of DCs in orchestrating immune responses and; therefore, the great interest in targeting these cells in novel vaccination strategies. We have reported examples of different approaches aimed at amplifying the efficiency of immunizations against cancer or infectious diseases. Indeed, the urgent need of vaccines is as relevant as before because of newly emerging diseases with ineffective current therapies. Deepen the mechanisms underlying these pathologies may provide cues on the more appropriate design of vaccines and by merging diverse tailoring strategies we could enforce the immune system. As a matter of fact, it is suggested to act on different fronts when designing new vaccines, since several factors must be considered: (i) targeting DC subsets specialized in initiating the desired cellular or humoral immunity/memory; (ii) adjuvants that strengthen and drive $\mathrm{T}$ and $\mathrm{B}$ cell responses; (iii) fine and optimized selection of the immunogenic ags to drive enforced responses; (iv) novel strategies to convey ags and adjuvants to DCs; (v) route of administration. Starting from these notions, in the last decades, enormous efforts have been made to tailor vaccination strategies. New technologies as well as recent advances have allowed extreme flexibility in designing vaccines and shaping the following outcomes. Nowadays, researchers do have smart tools to manipulate immune responses with prophylactic or therapeutic vaccinations. The abovementioned findings pave the way for possible therapeutic approaches, theoretically applicable to all pathological contexts. Despite this encouraging evidence, several limitations or issues still have to be overcome. Indeed, more than a few vaccines do not pass phases I of clinical trials either for toxicity issues and lack of immunogenicity in some individuals. What is missing? Part of the answer to this question could sit on human genetics and population variability. Syngeneic animal models are ideal settings in which the systems are pushed although they constitute a necessary and useful step preceding clinical trials.

Moreover, when translating vaccine testing from in vivo experiments on animals to ex vivo on human cells, often the opted choice are blood human cells, while in most of the cases vaccines will be administered in the skin, having a complete 
different DCs-based milieu (15). Crucially, Idoyaga and colleagues dissected the interindividual variability in skin-resident DCs, stressing the need of shedding light on the effects that genetics and environment imprint on DCs. It is compulsory to decode the complex scenario of human diversity to provide personalized therapies with increased efficacy. In the Omics era, systems biology and computational modeling integrate huge data-sets to address the urgent need of information on the global behavior. Indeed, Genome-wide association studies have provided insights into human genetics variants associated to the immunogenicity of vaccines $(179,180)$. Therefore, integration of "wet" evidence and "dry" notions may fasten the designing process and provide both efficient vaccine strategies and their predictive efficacy.

\section{REFERENCES}

1. Russell CD. Eradicating infectious disease: can we and should we? Front Immunol (2011) 2:1-3. doi:10.3389/fimmu.2011.00053

2. Finlay BB, McFadden G. Anti-immunology: evasion of the host immune system by bacterial and viral pathogens. Cell (2006) 124(4):767-82. doi:10.1016/j. cell.2006.01.034

3. Davenne T, McShane H. Why don't we have an effective tuberculosis vaccine yet? Expert Rev Vaccines (2016) 15(8):1009-13. doi:10.1586/14760584.2016. 1170599

4. Sahay B, Nguyen CQ, Yamamoto JK. Conserved HIV epitopes for an effective HIV vaccine. J Clin Cell Immunol (2017) 8(4):518. doi:10.4172/21559899.1000518

5. Hanahan D, Weinberg RA. Hallmarks of cancer: the next generation. Cell (2011) 144(5):646-74. doi:10.1016/j.cell.2011.02.013

6. Banchereau J, Steinman RM. Dendritic cells and the control of immunity. Nature (1998) 392:245-52. doi:10.1038/32588

7. Steinman RM, Chon ZA. Identification of a novel cell type in peripheral lymphoid organs of mice. I. Morphology, quantitation, tissue distribution. J Exp Med (1973) 137:1142-62. doi:10.1084/jem.137.5.1142

8. Steinman RM, Cohn ZA. Identification of a novel cell type in peripheral lympoid organs of mice. II. Functional properties in vitro. J Exp Med (1974) 139:380-97. doi:10.1084/jem.139.2.380

9. Granot T, Senda T, Carpenter DJ, Matsuoka N, Weiner J, Gordon CL, et al. Dendritic cells display subset and tissue-specific maturation dynamics over human life. Immunity (2017) 46(3):504-15. doi:10.1016/j.immuni.2017. 02.019

10. Guilliams M, Dutertre CA, Scott CL, McGovern N, Sichien D, Chakarov S, et al. Unsupervised high-dimensional analysis aligns dendritic cells across tissues and species. Immunity (2016) 45(3):669-84. doi:10.1016/j.immuni. 2016.08.015

11. Elpek KG, Bellemare-Pelletier A, Malhotra D, Reynoso ED, LukacsKornek V, DeKruyff RH, et al. Lymphoid organ-resident dendritic cells exhibit unique transcriptional fingerprints based on subset and site. PLoS One (2011) 6(8):e23921. doi:10.1371/journal.pone.0023921

12. Villani AC, Satija R, Reynolds G, Sarkizova S, Shekhar K, Fletcher J, et al. Single-cell RNA-seq reveals new types of human blood dendritic cells, monocytes, and progenitors. Science (2017) 356(6335):eaah4573. doi:10.1126/ science.aah4573

13. Heidkamp GF, Sander J, Lehmann CHK, Heger L, Eissing N, Baranska A, et al. Human lymphoid organ dendritic cell identity is predominantly dictated by ontogeny, not tissue microenvironment. Sci Immunol (2016) 1(6): eaai7677. doi:10.1126/sciimmunol.aai7677

14. Merad M, Sathe P, Helft J, Miller J, Mortha A. The dendritic cell lineage: ontogeny and function of dendritic cells and their subsets in the steady state and the inflamed setting. Annu Rev Immunol (2013) 31(1):563-604. doi:10.1146/annurev-immunol-020711-074950

15. Alcántara-Hernández M, Leylek R, Wagar LE, Engleman EG, Keler T, Marinkovich MP, et al. High-dimensional phenotypic mapping of human

\section{AUTHOR CONTRIBUTIONS}

All authors listed have made a substantial, direct, and intellectual contribution to the work and approved it for publication.

\section{FUNDING}

IZ is supported by NIH grant 1R01AI121066-01A1, 1R01DK115217, CCFA Senior Research Awards (412708), the Eleanor and Miles Shore 50th Anniversary Fellowship Program, and the Cariplo Foundation (2014-0859). FG is supported by Associazione Italiana per la Ricerca sul Cancro (IG 2016Id.18842), Cariplo Foundation (Grant 2014-0655), and Fondazione Regionale per la Ricerca Biomedica (FRRB).

dendritic cells reveals interindividual variation and tissue specialization. Immunity (2017) 47(6):1037-50.e6. doi:10.1016/j.immuni.2017.11.001

16. See P, Dutertre CA, Chen J, Günther P, McGovern N, Irac SE, et al. Mapping the human DC lineage through the integration of high-dimensional techniques. Science (2017) 356(6342):eaag3009. doi:10.1126/science.aag3009

17. Mildner A, Jung S. Development and function of dendritic cell subsets. Immunity (2014) 40(5):642-56. doi:10.1016/j.immuni.2014.04.016

18. Segura E, Valladeau-Guilemond J, Donnadieu M-H, Sastre-Garau X, Soumelis V, Amigorena S. Characterization of resident and migratory dendritic cells in human lymph nodes. J Exp Med (2012) 209(4):653-60. doi:10.1084/jem.20111457

19. Kashem SW, Igyarto BZ, Gerami-Nejad M, Kumamoto Y, Mohammed JA, Jarrett E, et al. Candida albicans morphology and dendritic cell subsets determine $\mathrm{T}$ helper cell differentiation. Immunity (2015) 42(2):356-66. doi:10.1016/j.immuni.2015.01.008

20. Igyártó BZ, Haley K, Ortner D, Bobr A, Gerami-Nejad M, Edelson BT, et al. Skin-resident murine dendritic cell subsets promote distinct and opposing antigen-specific T helper cell responses. Immunity (2011) 35(2):260-72. doi:10.1016/j.immuni.2011.06.005

21. Takeuchi O, Akira S. Pattern recognition receptors and inflammation. Cell (2010) 140(6):805-20. doi:10.1016/j.cell.2010.01.022

22. Ivanov S, Scallan JP, Kim KW, Werth K, Johnson MW, Saunders BT, et al. CCR7 and IRF4-dependent dendritic cells regulate lymphatic collecting vessel permeability. JClin Invest (2016) 126(4):1581-91. doi:10.1172/ JCI84518

23. Förster R, Braun A, Worbs T. Lymph node homing of T cells and dendritic cells via afferent lymphatics. Trends Immunol (2012) 33(6):271-80. doi:10.1016/j. it.2012.02.007

24. Braun A, Worbs T, Moschovakis GL, Halle S, Hoffmann K, Bölter J, et al. Afferent lymph-derived $\mathrm{T}$ cells and DCs use different chemokine receptor CCR7-dependent routes for entry into the lymph node and intranodal migration. Nat Immunol (2011) 12(9):879-87. doi:10.1038/ni.2085

25. Itano AA, McSorley SJ, Reinhardt RL, Ehst BD, Ingulli E, Rudensky AY, et al. Distinct dendritic cell populations sequentially present antigen to CD4 $\mathrm{T}$ cells and stimulate different aspects of cell-mediated immunity. Immunity (2003) 19(1):47-57. doi:10.1016/S1074-7613(03)00175-4

26. Vitali C, Mingozzi F, Broggi A, Barresi S, Zolezzi F, Bayry J, et al. Migratory, and not lymphoid-resident, dendritic cells maintain peripheral self-tolerance and prevent autoimmunity via induction of iTreg cells. Blood (2012) 120(6):1237-45. doi:10.1182/blood-2011-09-379776

27. Hawiger D, Inaba K, Dorsett $\mathrm{Y}$, Guo M, Mahnke K, Rivera M, et al. Dendritic cells induce peripheral $\mathrm{T}$ cell unresponsiveness under steady state conditions in vivo. J Exp Med (2001) 194(6):769-80. doi:10.1084/jem. 194.6.769

28. Steinman RM, Hawiger D, Nussenzweig MC. Tolerogenic dendritic cells. Annu Rev Immunol (2003) 21(1):685-711. doi:10.1146/annurev.immunol.21. 120601.141040

29. Kolls JK. Th17 cells in mucosal immunity and tissue inflammation. Semin Immunopathol (2010) 32(1):1-2. doi:10.1007/s00281-010-0198-8 
30. Zanoni I, Ostuni R, Capuano G, Collini M, Caccia M, Ronchi AE, et al. CD14 regulates the dendritic cell life cycle after LPS exposure through NFAT activation. Nature (2009) 460(7252):264-8. doi:10.1038/nature08118

31. Chen M, Wang YH, Wang Y, Huang L, Sandoval H, Liu YJ, et al. Dendritic cell apoptosis in the maintenance of immune tolerance. Science (2006) 311(5764):1160-4. doi:10.1126/science.1122545

32. Stranges PB, Watson J, Cooper CJ, Choisy-Rossi CM, Stonebraker AC, Beighton RA, et al. Elimination of antigen-presenting cells and autoreactive $\mathrm{T}$ cells by Fas contributes to prevention of autoimmunity. Immunity (2007) 26(5):629-41. doi:10.1016/j.immuni.2007.03.016

33. Tubo NJ, Fife BT, Pagan AJ, Kotov DI, Goldberg MF, Jenkins MK. Most microbe-specific naïve CD4+ T cells produce memory cells during infection. Science (2016) 351(6272):511-5. doi:10.1126/science.aad0483

34. Wen Y, Shi Y. Alum: an old dog with new tricks. Emerg Microbes Infect (2016) 5(3):e25. doi:10.1038/emi.2016.40

35. Kool M, Pétrilli V, De Smedt T, Rolaz A, Hammad H, van Nimwegen M, et al. Cutting edge: alum adjuvant stimulates inflammatory dendritic cells through activation of the NALP3 inflammasome. J Immunol (2008) 181(6):3755-9. doi:10.4049/jimmunol.181.6.3755

36. Li H, Willingham SB, Ting JP-Y, Re F. Cutting edge: inflammasome activation by alum and alum's adjuvant effect are mediated by NLRP3. J Immunol (2008) 181(1):17-21. doi:10.4049/jimmunol.181.1.17

37. Franchi L, Núñez G. The Nlrp3 inflammasome is critical for aluminum hydroxide-mediated IL-1 $\beta$ secretion but dispensable for adjuvant activity. Eur J Immunol (2008) 38(8):2085-9. doi:10.1002/eji.200838549

38. Marichal T, Ohata K, Bedoret D, Mesnil C, Sabatel C, Kobiyama K, et al. DNA released from dying host cells mediates aluminum adjuvant activity. Nat Med (2011) 17(8):996-1002. doi:10.1038/nm.2403

39. Gavin AL, Hoebe K, Duong B, Ota T, Martin C, Beutler B, et al. Adjuvantenhanced antibody receptor signaling. Science (2006) 314:1936-8. doi:10.1126/science.1135299

40. McKee AS, Munks MW, MacLeod MKL, Fleenor CJ, Van Rooijen N, KapplerJW, et al. Alum induces innate immune responses through macrophage and mast cell sensors, but these sensors are not required for alum to act as an adjuvant for specific immunity. J Immunol (2009) 183(7):4403-14. doi:10.4049/ jimmunol.0900164

41. Khameneh HJ, Ho AWS, Spreafico R, Derks H, Quek HQY, Mortellaro A. The Syk-NFAT-IL-2 pathway in dendritic cells is required for optimal sterile immunity elicited by alum adjuvants. J Immunol (2017) 198(1):196-204. doi:10.4049/jimmunol.1600420

42. Knudsen NP, Olsen A, Buonsanti C, Follmann F, Zhang Y, Coler RN, et al. Different human vaccine adjuvants promote distinct antigen-independent immunological signatures tailored to different pathogens. Sci Rep (2016) 6:1-13. doi:10.1038/srep19570

43. Cantisani R, Pezzicoli A, Cioncada R, Malzone C, De Gregorio E, D’Oro U, et al. Vaccine adjuvant MF59 promotes retention of unprocessed antigen in lymph node macrophage compartments and follicular dendritic cells. J Immunol (2015) 194(4):1717-25. doi:10.4049/jimmunol.1400623

44. Cioncada R, Maddaluno M, Vo HTM, Woodruff M, Tavarini S, Sammicheli C, et al. Vaccine adjuvant MF59 promotes the intranodal differentiation of antigen-loaded and activated monocyte-derived dendritic cells. PLoS One (2017) 12(10):e0185843. doi:10.1371/journal.pone.0185843

45. Szabo A, Gogolak P, Pazmandi K, Kis-Toth K, Riedl K, Wizel B, et al. The two-component adjuvant IC $31^{\circledR}$ boosts type I interferon production of human monocyte-derived dendritic cells via ligation of endosomal TLRs. PLoS One (2013) 8(2). doi:10.1371/journal.pone.0055264

46. Sekiya T, Yamagishi J, Gray JHV, Whitney PG, Martinelli A, Zeng W, et al. PEGylation of a TLR2-agonist-based vaccine delivery system improves antigen trafficking and the magnitude of ensuing antibody and CD8+T cell responses. Biomaterials (2017) 137:61-72. doi:10.1016/j.biomaterials.2017.05.018

47. Halliday A, Turner JD, Guimarães A, Bates PA, Taylor MJ. The TLR2/6 ligand PAM2CSK4 is a Th2 polarizing adjuvant in Leishmania major and Brugia malayi murine vaccine models. Parasit Vectors (2016) 9(1):1-9. doi:10.1186/ s13071-016-1381-0

48. Matsumoto M, Tatematsu M, Nishikawa F, Azuma M, Ishii N, Morii-Sakai A, et al. Defined TLR3-specific adjuvant that induces NK and CTL activation without significant cytokine production in vivo. Nat Commun (2015) 6:1-12. doi: $10.1038 /$ ncomms 7280
49. Zhu Q, Egelston C, Gagnon S, Sui Y, Belyakov IM, Klinman DM, et al. Using 3 TLR ligands as a combination adjuvant induces qualitative changes in $\mathrm{T}$ cell responses needed for antiviral protection in mice. J Clin Invest (2010) 120(2):607-16. doi:10.1172/JCI39293

50. Reed SG, Hsu FC, Carter D, Orr MT. The science of vaccine adjuvants: advances in TLR4 ligand adjuvants. Curr Opin Immunol (2016) 41:85-90. doi:10.1016/j.coi.2016.06.007

51. Lu Y, Swartz JR. Functional properties of flagellin as a stimulator of innate immunity. Sci Rep (2016) 6:1-11. doi:10.1038/srep18379

52. Buonsanti C, Balocchi C, Harfouche C, Corrente F, Galli Stampino L, Mancini F, et al. Novel adjuvant Alum-TLR7 significantly potentiates immune response to glycoconjugate vaccines. Sci Rep (2016) 6:1-12. doi:10.1038/srep29063

53. Bagnoli F, Fontana MR, Soldaini E, Mishra RP, Fiaschi L, Cartocci E, et al. Vaccine composition formulated with a novel TLR7-dependent adjuvant induces high and broad protection against Staphylococcus aureus. Proc Natl Acad Sci U S A (2015) 112(12):201424924. doi:10.1073/pnas. 1424924112

54. Van Hoeven N, Fox CB, Granger B, Evers T, Joshi SW, Nana GI, et al. A Formulated TLR7/8 agonist is a flexible, highly potent and effective adjuvant for pandemic influenza vaccines. Sci Rep (2017) 7:1-15. doi:10.1038/ srep46426

55. Song YC, Liu SJ. A TLR9 agonist enhances the anti-tumor immunity of peptide and lipopeptide vaccines via different mechanisms. Sci Rep (2015) 5:1-12. doi:10.1038/srep12578

56. Orr MT, Beebe EA, Hudson TE, Moon JJ, Fox CB, Reed SG, et al. A dual TLR agonist adjuvant enhances the immunogenicity and protective efficacy of the tuberculosis vaccine antigen ID93. PLoS One (2014) 9(1):e83884. doi:10.1371/journal.pone.0083884

57. Romero CD, Varma TK, Hobbs JB, Reyes A, Driver B, Sherwood ER. The toll-like receptor 4 agonist monophosphoryl lipid a augments innate host resistance to systemic bacterial infection. Infect Immun (2011) 79(9):3576-87. doi:10.1128/IAI.00022-11

58. Cui W, Joshi NS, Liu Y, Meng H, Kleinstein SH, Kaech SM. TLR4 ligands lipopolysaccharide and monophosphoryl lipid A differentially regulate effector and memory CD8+ T cell differentiation. J Immunol (2014) 192(9): 4221-32. doi:10.4049/jimmunol.1302569

59. Hamdy S, Molavi O, Ma Z, Haddadi A, Alshamsan A, Gobti Z, et al. Co-delivery of cancer-associated antigen and toll-like receptor 4 ligand in PLGA nanoparticles induces potent CD8+T cell-mediated anti-tumor immunity. Vaccine (2008) 26(39):5046-57. doi:10.1016/j.vaccine.2008. 07.035

60. Granucci F, Vizzardelli C, Pavelka N, Feau S, Persico M, Virzi E, et al. Inducible IL-2 production by dendritic cells revealed by global gene expression analysis. Nat Immunol (2001) 2(9):882-8. doi:10.1038/ni0901-882

61. Zanoni I, Granucci F. Regulation and dysregulation of innate immunity by NFAT signaling downstream of pattern recognition receptors (PRRs). Eur J Immunol (2012) 42(8):1924-31. doi:10.1002/eji.201242580

62. Wuest SC, Edwan JH, Martin JF, Han S, Perry JS, Cartagena CM, et al. A role for interleukin-2 trans-presentation in dendritic cell-mediated $\mathrm{T}$ cell activation in humans, as revealed by daclizumab therapy. Nat Med (2011) 17(5):604-9. doi:10.1038/nm.2365

63. Müller MR, Rao A. NFAT, immunity and cancer: a transcription factor comes of age. Nat Rev Immunol (2010) 10(9):645-56. doi:10.1038/nri2818

64. Goodridge HS, Simmons RM, Underhill DM. Dectin-1 stimulation by Candida albicans yeast or zymosan triggers NFAT activation in macrophages and dendritic cells. J Immunol (2007) 178(5):3107-15. doi:10.4049/ jimmunol.178.5.3107

65. Greenblatt MB, Aliprantis A, Hu B, Glimcher LH. Calcineurin regulates innate antifungal immunity in neutrophils. J Exp Med (2010) 207(5):923-31. doi:10.1084/jem.20092531

66. Yonekawa A, Saijo S, Hoshino Y, Miyake Y, Ishikawa E, Suzukawa M, et al. Dectin-2 is a direct receptor for mannose-capped lipoarabinomannan of mycobacteria. Immunity (2014) 41(3):402-13. doi:10.1016/j.immuni.2014. 08.005

67. Herbst S, Shah A, Mazon Moya M, Marzola V, Jensen B, Reed A, et al. Phagocytosis-dependent activation of a TLR9-BTK-calcineurin-NFAT pathway co-ordinates innate immunity to Aspergillus fumigatus. EMBO Mol Med (2015) 7(3):e201404556. doi:10.15252/emmm.201404556 
68. Santus W, Barresi S, Mingozzi F, Broggi A, Orlandi I, Stamerra G, et al. Skin infections are eliminated by cooperation of the fibrinolytic and innate immune systems. Sci Immunol (2017) 2(15):eaan2725. doi:10.1126/sciimmunol.aan 2725

69. Zanoni I, Spreafico R, Bodio C, Di Gioia M, Cigni C, Broggi A, et al. IL-15 cis presentation is required for optimal NK cell activation in lipopolysaccharide-mediated inflammatory conditions. Cell Rep (2013) 4(6):1235-49. doi:10.1016/j.celrep.2013.08.021

70. Granucci F, Zanoni I, Pavelka N, Van Dommelen SL, Andoniou CE, Belardelli F, et al. A contribution of mouse dendritic cell-derived IL-2 for NK cell activation. J Exp Med (2004) 200(3):287-95. doi:10.1084/jem.20040370

71. Zanoni I, Ostuni R, Barresi S, Di Gioia M, Broggi A, Costa B, et al. CD14 and NFAT mediate lipopolysaccharide- induced skin edema formation in mice. J Clin Invest (2012) 122(5):1747-57. doi:10.1172/JCI60688

72. Legler DF, Krause P, Scandella E, Singer E, Groettrup M. Prostaglandin E2 is generally required for human dendritic cell migration and exerts its effect via EP2 and EP4 receptors. J Immunol (2006) 176(2):966-73. doi:10.4049/jimmunol.176.2.966

73. Kastenmüller W, Torabi-Parizi P, Subramanian N, Lämmermann T, Germain RN. A spatially-organized multicellular innate immune response in lymph nodes limits systemic pathogen spread. Cell (2012) 150(6): 1235-48. doi:10.1016/j.cell.2012.07.021

74. Gonzalez SF, Lukacs-Kornek V, Kuligowski MP, Pitcher LA, Degn SE, Kim YA, et al. Capture of influenza by medullary dendritic cells via SIGN-R1 is essential for humoral immunity in draining lymph nodes. Nat Immunol (2010) 11(5):427-34. doi:10.1038/ni.1856

75. Roozendaal R, Mempel TR, Pitcher LA, Gonzalez SF, Verschoor A, Mebius RE, et al. Conduits mediate transport of low-molecular-weight antigen to lymph node follicles. Immunity (2009) 30(2):264-76. doi:10.1016/j.immuni. 2008.12.014

76. Gerner MY, Torabi-Parizi P, Germain RN. Strategically localized dendritic cells promote rapid $\mathrm{T}$ cell responses to lymph-borne particulate antigens. Immunity (2015) 42(1):172-85. doi:10.1016/j.immuni.2014.12.024

77. Gerner MY, Kastenmuller W, Ifrim I, Kabat J, Germain RN. Histo-cytometry: a method for highly multiplex quantitative tissue imaging analysis applied to dendritic cell subset microanatomy in lymph nodes. Immunity (2012) 37(2):364-76. doi:10.1016/j.immuni.2012.07.011

78. Iannacone M, Moseman EA, Tonti E, Bosurgi L, Junt T, Henrickson SE, et al. Subcapsular sinus macrophages prevent CNS invasion on peripheral infection with a neurotropic virus. Nature (2010) 465(7301):1079-83. doi:10.1038/nature09118

79. Sixt M, Kanazawa N, Selg M, Samson T, Roos G, Reinhardt DP, et al. The conduit system transports soluble antigens from the afferent lymph to resident dendritic cells in the T cell area of the lymph node. Immunity (2005) 22(1):19-29. doi:10.1016/j.immuni.2004.11.013

80. Farrell HE, Davis-Poynter N, Bruce K, Lawler C, Dolken L, Mach M, et al. Lymph node macrophages restrict murine cytomegalovirus dissemination. J Virol (2015) 89(14):7147-58. doi:10.1128/JVI.00480-15

81. Frederico B, Chao B, Lawler C, May JS, Stevenson PG. Subcapsular sinus macrophages limit acute gammaherpesvirus dissemination. J Gen Virol (2015) 96(8):2314-27. doi:10.1099/vir.0.000140

82. Tomura M, Hata A, Matsuoka S, Shand FH, Nakanishi Y, Ikebuchi R, et al. Tracking and quantification of dendritic cell migration and antigen trafficking between the skin and lymph nodes. Sci Rep (2014) 4:1-11. doi:10.1038/ srep06030

83. Kissenpfennig A, Henri S, Dubois B, Laplace-Builhé C, Perrin P, Romani N, et al. Dynamics and function of Langerhans cells in vivo: dermal dendritic cells colonize lymph node areasdistinct from slower migrating Langerhans cells. Immunity (2005) 22(5):643-54. doi:10.1016/j.immuni.2005. 04.004

84. Radtke AJ, Kastenmüller W, Espinosa DA, Gerner MY, Tse SW, Sinnis P, et al. Lymph-node resident CD8a+ dendritic cells capture antigens from migratory malaria sporozoites and induce CD8+ T cell responses. PLoS Pathog (2015) 11(2):e1004637. doi:10.1371/journal.ppat.1004637

85. Iezzi G, Fröhlich A, Ernst B, Ampenberger F, Saeland S, Glaichenhaus N, et al. Lymph node resident rather than skin-derived dendritic cells initiate specific T cell responses after Leishmania major infection. J Immunol (2006) 177(2):1250-6. doi:10.4049/jimmunol.177.2.1250
86. Heath WR, Belz GT, Behrens GM, Smith CM, Forehan SP, Parish IA, et al. Cross-presentation, dendritic cell subsets, and the generation of immunity to cellular antigens. Immunol Rev (2004) 199:9-26. doi:10.1111/j.01052896.2004.00142.x

87. Thacker RI, Janssen EM. Cross-presentation of cell-associated antigens by mouse splenic dendritic cell populations. Front Immunol (2012) 3:41. doi:10.3389/fimmu.2012.00041

88. Brewitz A, Eickhoff S, Dähling S, Quast T, Bedoui S, Kroczek RA, et al. CD8+T cells orchestrate pDC-XCR1+dendritic cell spatial and functional cooperativity to optimize priming. Immunity (2017) 46(2):205-19. doi:10.1016/j.immuni.2017.01.003

89. Allan RS, Waithman J, Bedoui S, Jones CM, Villadangos JA, Zhan Y, et al. Migratory dendritic cells transfer antigen to a lymph node-resident dendritic cell population for efficient CTL priming. Immunity (2006) 25(1):153-62. doi:10.1016/j.immuni.2006.04.017

90. Mount AM, Smith CM, Kupresanin F, Stoermer K, Heath WR, Belz GT. Multiple dendritic cell populations activate CD4+ T cells after viral stimulation. PLoS One (2008) 3(2):e1691. doi:10.1371/journal.pone. 0001691

91. Bedoui S, Whitney PG, Waithman J, Eidsmo L, Wakim L, Caminschi I, et al. Cross-presentation of viral and self antigens by skin-derived CD103+ dendritic cells. Nat Immunol (2009) 10(5):488-95. doi:10.1038/ni.1724

92. Kitano M, Yamazaki C, Takumi A, Ikeno T, Hemmi H, Takahashi N, et al. Imaging of the cross-presenting dendritic cell subsets in the skin-draining lymph node. Proc Natl Acad Sci U S A (2016) 113(4):1044-9. doi:10.1073/ pnas. 1513607113

93. Waithman J, Zanker D, Xiao K, Oveissi S, Wylie B, Ng R, et al. Resident CD8+ and migratory CD103+ dendritic cells control CD8 T cell immunity during acute influenza infection. PLoS One (2013) 8(6):e66136. doi:10.1371/ journal.pone.0066136

94. Haniffa M, Shin A, Bigley V, McGovern N, Teo P, See P, et al. Human tissues contain CD141hiCross-presenting dendritic cells with functiona homology to mouse CD103+nonlymphoid dendritic cells. Immunity (2012) 37(1):60-73. doi:10.1016/j.immuni.2012.04.012

95. Edelson BT, KC W, Juang R, Kohyama M, Benoit LA, Klekotka PA, et al. Peripheral CD103 + dendritic cells form a unified subset developmentally related to CD8 $\alpha+$ conventional dendritic cells. J Exp Med (2010) 207(4): 823-36. doi:10.1084/jem.20091627

96. Dorner BG, Dorner MB, Zhou X, Opitz C, Mora A, Güttler S, et al. Selective expression of the chemokine receptor XCR1 on cross-presenting dendritic cells determines cooperation with CD8+ T cells. Immunity (2009) 31(5):823-33. doi:10.1016/j.immuni.2009.08.027

97. Ravindran R, Rusch L, Itano A, Jenkins MK, McSorley SJ. CCR6-dependent recruitment of blood phagocytes is necessary for rapid CD4 T cell responses to local bacterial infection. Proc Natl Acad Sci U S A (2007) 104(29): 12075-80. doi:10.1073/pnas.0701363104

98. Van VQ, Lesage S, Bouguermouh S, Gautier P, Rubio M, Levesque M, et al. Expression of the self-marker CD47 on dendritic cells governs their trafficking to secondary lymphoid organs. EMBO J (2006) 25(23):5560-8. doi:10.1038/sj.emboj.7601415

99. Stoitzner P, Green LK, Jung JY, Price KM, Tripp CH, Malissen B, et al. Tumor immunotherapy by epicutaneous immunization requires Langerhans cells. J Immunol (2008) 180(3):1991-8. doi:10.4049/jimmunol. 180.3.1991

100. Wang L, Bursch LS, Kissenpfennig A, Malissen B, Jameson SC, Hogquist KA. Langerin expressing cells promote skin immune responses under defined conditions. J Immunol (2008) 180(7):4722-7. doi:10.4049/jimmunol.180. 7.4722

101. Seneschal J, Jiang X, Kupper TS. Langerin + dermal DC, but not Langerhans cells, are required for effective CD8-mediated immune responses after skin scarification with vaccinia virus. J Invest Dermatol (2014) 134(3):686-94 doi:10.1038/jid.2013.418

102. Kaplan DH. Langerhans cells: not your average dendritic cell. Trends Immunol (2010) 31(12):437. doi:10.1016/j.it.2010.10.003

103. Igyarto BZ, Jenison MC, Dudda JC, Roers A, Müller W, Koni PA, et al. Langerhans cells suppress contact hypersensitivity responses via cognate CD4 interaction and Langerhans cell-derived IL-10. J Immunol (2009) 183(8):5085-93. doi:10.4049/jimmunol.0901884 
104. Mutyambizi K, Berger CL, Edelson RL. The balance between immunity and tolerance: the role of Langerhans cells. Cell Mol Life Sci (2009) 66(5):831-40. doi:10.1007/s00018-008-8470-y

105. Eickhoff S, Brewitz A, Gerner MY, Klauschen F, Komander K, Hemmi H, et al. Robust anti-viral immunity requires multiple distinct $\mathrm{T}$ cell-dendritic cell interactions. Cell (2015) 162(6):1322-37. doi:10.1016/j.cell.2015.08.004

106. Allenspach EJ, Lemos MP, Porrett PM, Turka LA, Laufer TM. Migratory and lymphoid-resident dendritic cells cooperate to efficiently prime naive CD4 T cells. Immunity (2008) 29(5):795-806. doi:10.1016/j.immuni.2008.08.013

107. Sen D, Forrest L, Kepler TB, Parker I, Cahalan MD. Selective and site-specific mobilization of dermal dendritic cells and Langerhans cells by Th1- and Th2-polarizing adjuvants. Proc Natl Acad Sci U S A (2010) 107(18):8334-9. doi:10.1073/pnas.0912817107

108. Antonialli R, Sulczewski FB, Amorim KNDS, Almeida BDS, Ferreira NS, Yamamoto MM, et al. CpG oligodeoxinucleotides and flagellin modulate the immune response to antigens targeted to $\operatorname{CD} 8 \alpha+$ and $C D 8 \alpha-$ conventional dendritic cell subsets. Front Immunol (2017) 8:1727. doi:10.3389/ fimmu.2017.01727

109. Rosalia RA, Cruz LJ, van Duikeren S, Tromp AT, Silva AL, Jiskoot W, et al. CD40-targeted dendritic cell delivery of PLGA-nanoparticle vaccines induce potent anti-tumor responses. Biomaterials (2015) 40:88-97. doi:10.1016/j. biomaterials.2014.10.053

110. Trumpfheller C, Finke JS, López CB, Moran TM, Moltedo B, Soares H, et al. Intensified and protective $\mathrm{CD} 4{ }^{+} \mathrm{T}$ cell immunity in mice with anti-dendritic cell HIV gag fusion antibody vaccine. J Exp Med (2006) 203(3):607-17. doi:10.1084/jem.20052005

111. Boscardin SB, Hafalla JC, Masilamani RF, Kamphorst AO, Zebroski HA, Rai U, et al. Antigen targeting to dendritic cells elicits long-lived T cell help for antibody responses. JExp Med (2006) 203(3):599-606. doi:10.1084/ jem.20051639

112. Bonifaz LC, Bonnyay DP, Charalambous A, Darguste DI, Fujii S, Soares H, et al. In vivo targeting of antigens to maturing dendritic cells via the DEC205 receptor improves T cell vaccination. J Exp Med (2004) 199(6):815-24. doi:10.1084/jem.20032220

113. Beckman RA, Weiner LM, Davis HM. Antibody constructs in cancer therapy: protein engineering strategies to improve exposure in solid tumors. Cancer (2007) 109(2):170-9. doi:10.1002/cncr.22402

114. Granucci F, Prosperi D. Nanoparticles: "magic bullets" for targeting the immune system. Semin Immunol (2017) 34:1-2. doi:10.1016/j.smim.2017. 10.002

115. Prosperi D, Colombo M, Zanoni I, Granucci F. Drug nanocarriers to treat autoimmunity and chronic inflammatory diseases. Semin Immunol (2017) 34:61-7. doi:10.1016/j.smim.2017.08.010

116. Boraschi D, Italiani P, Palomba R, Decuzzi P, Duschl A, Fadeel B, et al. Nanoparticles and innate immunity: new perspectives on host defence. Semin Immunol (2017) 34:33-51. doi:10.1016/j.smim.2017.08.013

117. Kantoff PW, Schuetz TJ, Blumenstein BA, Glode LM, Bilhartz DL, Wyand M, et al. Overall survival analysis of a phase II randomized controlled trial of a poxviral-based PSA-targeted immunotherapy in metastatic castrationresistant prostate cancer. J Clin Oncol (2010) 28(7):1099-105. doi:10.1200/ JCO.2009.25.0597

118. Yang Z, Xu M, Jia Z, Zhang Y, Wang L, Zhang H, et al. A novel antigen delivery system induces strong humoral and CTL immune responses. Biomaterials (2017) 134:51-63. doi:10.1016/j.biomaterials.2017.04.035

119. Rincon-Restrepo M, Mayer A, Hauert S, Bonner DK, Phelps EA, Hubbell JA, et al. Vaccine nanocarriers: coupling intracellular pathways and cellular biodistribution to control CD4 vs CD8 T cell responses. Biomaterials (2017) 132:48-58. doi:10.1016/j.biomaterials.2017.03.047

120. Kim SY, Noh YW, Kang TH, Kim JE, Kim S, Um SH, et al. Synthetic vaccine nanoparticles target to lymph node triggering enhanced innate and adaptive antitumor immunity. Biomaterials (2017) 130:56-66. doi:10.1016/j. biomaterials.2017.03.034

121. Waeckerle-Men Y, Groettrup M. PLGA microspheres for improved antigen delivery to dendritic cells as cellular vaccines. Adv Drug Deliv Rev (2005) 57:475-82. doi:10.1016/j.addr.2004.09.007

122. Maji M, Mazumder S, Bhattacharya S, Choudhury ST, Sabur A, Shadab M, et al. A lipid based antigen delivery system efficiently facilitates MHC class-I antigen presentation in dendritic cells to stimulate CD8+T cells. Sci Rep (2016) 6:1-12. doi:10.1038/srep27206
123. Bachem A, Güttler S, Hartung E, Ebstein F, Schaefer M, Tannert A, et al. Superior antigen cross-presentation and XCR1 expression define human $\mathrm{CD} 11 \mathrm{c}{ }^{+} \mathrm{CD} 141{ }^{+}$cells as homologues of mouse CD8 ${ }^{+}$dendritic cells. J Exp Med (2010) 207(6):1273-81. doi:10.1084/jem.20100348

124. Huysamen C, Willment JA, Dennehy KM, Brown GD. CLEC9A is a novel activation C-type lectin-like receptor expressed on BDCA3+ dendritic cells and a subset of monocytes. J Biol Chem (2008) 283(24):16693-701. doi:10.1074/jbc.M709923200

125. Poulin LF, Salio M, Griessinger E, Anjos-Afonso F, Craciun L, Chen JL, et al. Characterization of human DNGR-1 + BDCA3 ${ }^{+}$leukocytes as putative equivalents of mouse CD8 $\alpha+$ dendritic cells. J Exp Med (2010) 207(6): 1261-71. doi:10.1084/jem.20092618

126. Kroczek RA, Henn V. The role of XCR1 and its ligand XCL1 in antigen cross-presentation by murine and human dendritic cells. Front Immunol (2012) 3:1-5. doi:10.3389/fimmu.2012.00014

127. Schreibelt G, Klinkenberg LJ, Cruz LJ, Tacken PJ, Tel J, Kreutz M, et al. The C-type lectin receptor CLEC9A mediates antigen uptake and (cross-) presentation by human blood BDCA3+ myeloid dendritic cells. Blood (2012) 119(10):2284-92. doi:10.1182/blood-2011-08-373944

128. Li J, Ahmet F, Sullivan LC, Brooks AG, Kent SJ, De Rose R, et al. Antibodies targeting Clec $9 \mathrm{~A}$ promote strong humoral immunity without adjuvant in mice and non-human primates. Eur J Immunol (2015) 45(3):854-64. doi:10.1002/ eji.201445127

129. Caminschi I, Ahmet F, Kitsoulis S, Teh JS, Lo JC, Rizzitelli A, et al. The dendritic cell subtype restricted C-type lectin Clec9A is a target for vaccine enhancement. Blood (2008) 112(8):3264-73. doi:10.1182/blood-200805-155176

130. Lahoud MH, Ahmet F, Kitsoulis S, Wan SS, Vremec D, Lee CN, et al. Targeting antigen to mouse dendritic cells via Clec9A induces potent CD4 $\mathrm{T}$ cell responses biased toward a follicular helper phenotype. JImmunol (2011) 187(2):842-50. doi:10.4049/jimmunol.1101176

131. Kato Y, Zaid A, Davey GM, Mueller SN, Nutt SL, Zotos D, et al. Targeting antigen to Clec9A primes follicular Th cell memory responses capable of robust recall. J Immunol (2015) 195(3):1006-14. doi:10.4049/jimmunol. 1500767

132. Park H-Y, Light A, Lahoud MH, Caminschi I, Tarlinton DM, Shortman K. Evolution of B cell responses to Clec9A-targeted antigen. J Immunol (2013) 191(10):4919-25. doi:10.4049/jimmunol.1301947

133. Tullett KM, Leal Rojas IM, Minoda Y, Tan PS, Zhang JG, Smith C, et al. Targeting CLEC9A delivers antigen to human CD141+ DC for CD4+ and CD8+T cell recognition. JCI Insight (2016) 1(7):1-12. doi:10.1172/jci. insight.87102

134. Park HY, Tan PS, Kavishna R, Ker A, Lu J, Chan CEZ, et al. Enhancing vaccine antibody responses by targeting Clec9A on dendritic cells. NPJ Vaccines (2017) 2(1):31. doi:10.1038/s41541-017-0033-5

135. Sancho D, Mourão-Sá D, Joffre OP, Schulz O, Rogers NC, Pennington DJ, et al. Tumor therapy in mice via antigen targeting to a novel, DC-restricted C-type lectin. J Clin Invest (2008) 118(6):2098-110. doi:10.1172/JCI34584

136. Jiang W, Swiggard WJ, Heufler C, Peng M, Mirza A, Steinman RM, et al. The receptor DEC-205 expressed by dendritic cells and thymic epithelial cells is involved in antigen processing. Nature (1995) 375(6527):151-5. doi:10.1038/375151a0

137. Shrimpton RE, Butler M, Morel AS, Eren E, Hue SS, Ritter MA. CD205 (DEC-205): a recognition receptor for apoptotic and necrotic self. Mol Immunol (2009) 46(6):1229-39. doi:10.1016/j.molimm.2008.11.016

138. Kato M, McDonald KJ, Khan S, Ross IL, Vuckovic S, Chen K, et al. Expression of human DEC-205 (CD205) multilectin receptor on leukocytes. Int Immunol (2006) 18(6):857-69. doi:10.1093/intimm/dxl022

139. Mahnke K, Guo M, Lee S, Sepulveda H, Swain SL, Nussenzweig M, et al. The dendritic cell receptor for endocytosis, DEC-205, can recycle and enhance antigen presentation via major histocompatibility complex class II - positive lysosomal compartments. J Cell Biol (2000) 151(3):673-83. doi:10.1083/ jcb.151.3.673

140. Guo M, Gong S, Maric S, Misulovin Z, Pack M, Mahnke K, et al. A monoclonal antibody to the DEC-205 endocytosis receptor on human dendritic cells. Hum Immunol (2000) 61(8):729-38. doi:10.1016/S0198-8859 (00)00144-0

141. Bonifaz L, Bonnyay D, Mahnke K, Rivera M, Nussenzweig MC, Steinman RM. Efficient targeting of protein antigen to the dendritic cell receptor DEC-205 
in the steady state leads to antigen presentation on major histocompatibility complex class I products and peripheral CD8 + T cell tolerance. J Exp Med (2002) 196(12):1627-38. doi:10.1084/jem.20021598

142. Tel J, Benitez-Ribas D, Hoosemans S, Cambi A, Adema GJ, Figdor CG, et al. DEC-205 mediates antigen uptake and presentation by both resting and activated human plasmacytoid dendritic cells. Eur J Immunol (2011) 41(4):1014-23. doi:10.1002/eji.201040790

143. Bozzacco L, Trumpfheller C, Siegal FP, Mehandru S, Markowitz M, Carrington M, et al. DEC-205 receptor on dendritic cells mediates presentation of HIV gag protein to CD8+ T cells in a spectrum of human MHC I haplotypes. Proc Natl Acad Sci U S A (2007) 104(4):1289-94. doi:10.1073/pnas.0610383104

144. Sartorius R, D’Apice L, Trovato M, Cuccaro F, Costa V, De Leo MG, et al. Antigen delivery by filamentous bacteriophage fd displaying an anti-DEC-205 single-chain variable fragment confers adjuvanticity by triggering a TLR9mediated immune response. EMBO Mol Med (2015) 7(7):973-88. doi:10.15252/ emmm.201404525

145. Sartorius R, Bettua C, D'Apice L, Caivano A, Trovato M, Russo D, et al. Vaccination with filamentous bacteriophages targeting DEC-205 induces DC maturation and potent anti-tumor T-cell responses in the absence of adjuvants. Eur JImmunol (2011) 41(9):2573-84. doi:10.1002/eji. 201141526

146. Caminschi I, Meuter S, Heath WR. DEC-205 is a cell surface receptor for CpG oligonucleotides. Oncoimmunology (2013) 2(3):e23128. doi:10.4161/ onci. 23128

147. Becker T, Hartl FU, Wieland F. CD40, an extracellular receptor for binding and uptake of Hsp70-peptide complexes. J Cell Biol (2002) 158(7):1277-85. doi:10.1083/jcb.200208083

148. Schjetne KW, Fredriksen AB, Bogen B. Delivery of antigen to CD40 induces protective immune responses against tumors. JImmunol (2007) 178(7): 4169-76. doi:10.4049/jimmunol.178.7.4169

149. Xu H, Zhao G, Huang X, Ding Z, Wang J, Wang X, et al. CD40-expressing plasmid induces anti-CD40 antibody and enhances immune responses to DNA vaccination. JGene Med (2010) 12(6):97-106. doi:10.1002/ jgm. 1412

150. Chen J, Zurawski G, Zurawski S, Wang Z, Akagawa K, Oh S, et al. A novel vaccine for mantle cell lymphoma based on targeting cyclin D1 to dendritic cells via CD40 hematology \& oncology. J Hematol Oncol (2015) 8(1):1-15. doi:10.1186/s13045-015-0131-7

151. Mingozzi F, Spreafico R, Gorletta T, Cigni C, Di Gioia M, Caccia M, et al. Prolonged contact with dendritic cells turns lymph node-resident NK cells into anti-tumor effectors. EMBO Mol Med (2016) 8(9):1039-51. doi:10.15252/emmm.201506164

152. Dissanayake D, Murakami K, Tran MD, Elford AR, Millar DG, Ohashi PS. Peptide-pulsed dendritic cells have superior ability to induce immune-mediated tissue destruction compared to peptide with adjuvant. PLoS One (2014) 9(3):e92380. doi:10.1371/journal.pone.0092380

153. Bijker MS, van den Eeden SJ, Franken KL, Melief CJ, van der Burg SH, Offringa R. Superior induction of anti-tumor CTL immunity by extended peptide vaccines involves prolonged, DC-focused antigen presentation. Eur J Immunol (2008) 38:1033-42. doi:10.1002/eji.200737995

154. Rosalia RA, Quakkelaar ED, Redeker A, Khan S, Camps M, Drijfhout JW, et al. Dendritic cells process synthetic long peptides better than whole protein, improving antigen presentation and T-cell activation. Eur J Immunol (2013) 43:2554-65. doi:10.1002/eji.201343324

155. Kenter GG, Welters MJ, Valentijn AR, Lowik MJ, Berends-van der Meer DM, Vloon AP, et al. Vaccination against HPV-16 oncoproteins for vulvar intraepithelial neoplasia. N Engl J Med (2009) 361:1838-47. doi:10.1056/ NEJMoa0810097

156. Sabbatini P, Tsuji T, Ferran L, Ritter E, Sedrak C, Tuballes K, et al. Phase I trial of overlapping long peptides from a tumor self- antigen and poly-ICLC shows rapid induction of integrated immune response in ovarian cancer patients. Clin Cancer Res (2012) 18:6497-509. doi:10.1158/1078-0432. CCR-12-2189

157. Zeestraten EC, Speetjens FM, Welters MJ, Saadatmand S, Stynenbosch LF, Jongen R, et al. Addition of interferon- $\alpha$ to the p53-SLP V vaccine results in increased production of interferon- $c$ in vaccinated colorectal cancer patients: a phase I/II clinical trial. Int J Cancer (2013) 132:1581-91. doi:10.1002/ ijc. 27819
158. Speetjens FM, Kuppen PJ, Welters MJ, Essahsah F, Voet van den Brink AM, Lantrua MG, et al. Induction of p53-specific immunity by a p53 synthetic long peptide vaccine in patients $\mathrm{T}$ reated for metastatic colorectal cancer. Clin Cancer Res (2009) 15(3):1086-96. doi:10.1158/1078-0432.CCR08-2227

159. Aarntzen EH, Schreibelt G, Bol K, Lesterhuis WJ, Croockewit AJ, de Wilt $\mathrm{JH}$, et al. Vaccination with mRNA-electroporated dendritic cells induces robust tumor antigen-specific $\mathrm{CD} 4+$ and $\mathrm{CD} 8+\mathrm{T}$ cells responses in stage III and IV melanoma patients. Clin Cancer Res (2012) 18(19):5460-70. doi:10.1158/1078-0432.CCR-11-3368

160. Bryson PD, Han X, Truong N, Wang P. Breast cancer vaccines delivered by dendritic cell-targeted lentivectors induce potent antitumor immune responses and protect mice from mammary tumor growth. Vaccine (2017) 35(43):5842-9. doi:10.1016/j.vaccine.2017.09.017

161. Schumacher TN, Schreiber RD. Neoantigens in cancer immunotherapy. Science (2015) 348(6230):69-74. doi:10.1126/science.aaa4971

162. Tanyi JL, Bobisse S, Ophir E, Tuyaerts S, Roberti A, Genolet R, et al. Personalized cancer vaccine effectively mobilizes antitumor $\mathrm{T}$ cell immunity in ovarian cancer. Sci Transl Med (2018) 5931(April):1-15. doi:10.1126/ scitranslmed.aao5931

163. Sahin U, Derhovanessian E, Miller M, Kloke BP, Simon P, Löwer M, et al. Personalized RNA mutanome vaccines mobilize poly-specific therapeutic immunity against cancer. Nature (2017) 547(7662):222-6. doi:10.1038/ nature 23003

164. Ott PA, Hu Z, Keskin DB, Shukla SA, Sun J, Bozym DJ, et al. An immunogenic personal neoantigen vaccine for patients with melanoma. Nature (2017) 547(7662):217-21. doi:10.1038/nature22991

165. Laxmanan S, Robertson SW, Wang E, Lau JS, David M, Mukhopadhyay D. Vascular endothelial growth factor impairs the functional ability of dendritic cells through Id pathways. Biochem Biophys Res Commun (2005) 334(1): 193-8. doi:10.1016/j.bbrc.2005.06.065

166. Mimura K, Kono K, Takahashi A, Kawaguchi Y, Fujii H. Vascular endothelial growth factor inhibits the function of human mature dendritic cells mediated by VEGF receptor-2. Cancer Immunol Immunother (2007) 56:761-70. doi:10.1007/s00262-006-0234-7

167. Baghdadi M, Endo H, Takano A, Ishikawa K, Kameda Y, Wada H, et al. High co-expression of IL-34 and M-CSF correlates with tumor progression and poor survival in lung cancers. Sci Rep (2018) 8(1):418. doi:10.1038/ s41598-017-18796-8

168. Kao JY, Gong Y, Chen C, Zheng Q-D, Chen J. Tumor-derived TGF- $\beta$ reduces the efficacy of dendritic cell/tumor fusion vaccine. J Immunol (2018) 170:3806-11. doi:10.4049/jimmunol.170.7.3806

169. Zhao S, Wu D, Wu P, Wang Z, Huang J. Serum IL-10 predicts worse outcome in cancer patients: a meta-analysis. PLoS One (2015) 10(10):e0139598. doi:10.1371/journal.pone.0139598

170. Oft M. IL-10: master switch from tumor-promoting in flammation to antitumor immunity. Cancer Immunol Res (2014) 2:194-200. doi:10.1158/ 2326-6066.CIR-13-0214

171. Verronèse E, Delgado A, Valladeau-Guillemond J, Garin G, Guillemaut S, Tredan $\mathrm{O}$, et al. Immune cell dysfunctions in breast cancer patients detected through whole blood multi-parametric flow cytometry assay. Oncoimmunology (2016) 5(3):e1100791. doi:10.1080/2162402X.2015. 1100791

172. Imai K, Minamiya Y, Koyota S, Ito M, Saito H, Sato Y, et al. Inhibition of dendritic cell migration by transforming growth factor-b 1 increases tumor-draining lymph node metastasis. JExp Clin Cancer Res (2012) 31(3):1-9. doi:10.1186/1756-9966-31-3

173. Schreibelt G, Bol KF, Westdorp H, Wimmers F, Aarntzen EH, Duivemande Boer $\mathrm{T}$, et al. Effective clinical responses in metastatic melanoma patients after vaccination with primary myeloid dendritic cells. Clin Cancer Res (2016) 22(9):2155-66. doi:10.1158/1078-0432.CCR-15-2205

174. Anandasabapathy N, Feder R, Mollah S, Tse SW, Longhi MP, Mehandru S, et al. Classical Flt3L-dependent dendritic cells control immunity to protein vaccine. J Exp Med (2014) 211(9):1875-91. doi:10.1084/jem.20131397

175. Kreiter S, Diken M, Selmi A, Diekmann J, Attig S, Hüsemann Y, et al. FLT3 ligand enhances the cancer therapeutic potency of naked RNA vaccines. Cancer Res (2011) 71(19):6132-43. doi:10.1158/0008-5472.CAN11-0291 
176. Perez-Shibayama C, Gil-Cruz C, Nussbacher M, Allgäuer E, CervantesBarragan L, Züst R, et al. Dendritic cell-specific delivery of Flt3L by coronavirus vectors secures induction of therapeutic antitumor immunity. PLoS One (2013) 8(11):e81442. doi:10.1371/journal.pone.0081442

177. Antonios JP, Soto H, Everson RG, Orpilla J, Moughon D, Shin N, et al. PD-1 blockade enhances the vaccination-induced immune response in glioma. JCI Insight (2016) 1(10):e87059. doi:10.1172/jci.insight.87059

178. Zheng X, Koropatnick J, Chen D, Velenosi T, Ling H, Min W, et al. Silencing IDO in dendritic cells: a novel approach to enhance cancer immunotherapy in a murine breast cancer model. Int J Cancer (2013) 132:967-77. doi:10.1002/ ijc. 27710

179. Mentzer AJ, O'Connor D, Pollard AJ, Hill AVS. Searching for the human genetic factors standing in the way of universally effective vaccines. Philos Trans R Soc Lond B Biol Sci (2015) 370(1671):20140341-20140341. doi:10.1098/rstb.2014.0341
180. Tsang JS, Schwartzberg PL, Kotliarov Y, Biancotto A, Xie Z, Germain RN, et al. Global analyses of human immune variation reveal baseline predictors of postvaccination responses. Cell (2014) 157(2):499-513. doi:10.1016/j.cell.2014.03.031

Conflict of Interest Statement: The authors declare that the research was conducted in the absence of any commercial or financial relationships that could be construed as a potential conflict of interest.

Copyright (c) 2018 Gornati, Zanoni and Granucci. This is an open-access article distributed under the terms of the Creative Commons Attribution License (CC BY). The use, distribution or reproduction in other forums is permitted, provided the original author(s) and the copyright owner are credited and that the original publication in this journal is cited, in accordance with accepted academic practice. No use, distribution or reproduction is permitted which does not comply with these terms. 